\title{
Investigation of Biochar Production from Copyrolysis of Rice Husk and Plastic
}

\author{
Nichakorn Wantaneeyakul,* Ketwalee Kositkanawuth, Scott Q. Turn, and Jinxia Fu
}

Cite This: ACS Omega 2021, 6, 28890-28902

Read Online

ACCESS

Lلll Metrics \& More

Article Recommendations

Supporting Information

ABSTRACT: Biomass renewable energy has become a major target of the Thailand Alternative Energy Development Plan (AEDP) since the country's economy is largely based on agricultural production. Rice husk $(\mathrm{RH})$ is one of the most common agricultural residues in Thailand. This research aims to investigate yields and properties of biochar produced from copyrolysis of $\mathrm{RH}$ and plastic (high-density polyethylene (HDPE)) at different ratios, temperatures, and holding times. For both individual and copyrolysis, the temperature variation generated more pronounced effects than the holding time variation on both biochar yields and properties. For individual pyrolysis of

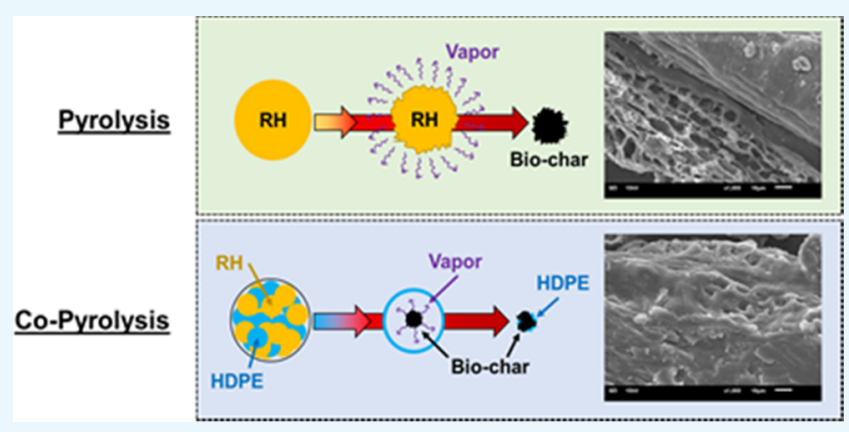
$\mathrm{RH}$, the maximum biochar yield of $\sim 54 \mathrm{wt} \%$ was obtained at 400 ${ }^{\circ} \mathrm{C}$. A shift in temperature from 400 to $600{ }^{\circ} \mathrm{C}$ resulted in $\mathrm{RH}$ biochars with higher fixed carbon (FC) and carbon (C) contents by 1.11-1.28 and 1.06-1.22 times, respectively, while undetectable changes in higher heating values (HHVs) were noticed. For copyrolysis, obvious negative synergistic effects were observed due to the radical interaction between the rich $\mathrm{H}$ content of HDPE and RH biochars, which resulted in lower biochar yields as compared to the theoretical estimation based on individual pyrolysis values. However, the addition of HDPE positively impacted the FC and C contents, especially when 10 and 20 wt \% HDPE were added to the feedstock. Besides, higher HDPE blending ratios resulted in biochars with improved HHVs, and >1.5 times improvement in HHV was reported in the biochar with 50 wt \% HDPE addition in comparison with RH biochar obtained under the same conditions. In summary, biochars generated in this study have the potential to be utilized as a solid fuel or soil amendment.

\section{INTRODUCTION}

The use of renewable energy from alternative resources including wind, solar, biomass, hydro, geothermal, tidal, and nuclear has grown significantly in the last few decades. The International Energy Agency ${ }^{1}$ reported a similar annual growth rate of renewable energy sources $(2.0 \%)$ and world total energy supply (1.8\%) since 1990. Asia had the highest consumption of renewable energy, accounting for $\sim 41 \%$ of the world total in 2018 , of which $62 \%$ was derived from bioenergy. ${ }^{2}$ In developing countries, biomass is more attractive than other renewable energy resources, as it is seasonally abundant from a wide variety of agriculture residues and is simple to utilize in all forms. ${ }^{1}$ Global biofuel consumption has increased by $\sim 31 \%$ from $50.5 \mathrm{EJ}$ in 2005 to $66.2 \mathrm{EJ}$ in $2018 .^{2}$

The Thai government promoted the usage of renewable energy for electricity, heat, and biofuel production through the 2015 Thailand Alternative Energy Development Plan (AEDP). The AEDP has set a target that renewable energy would account for $30 \%$ of total energy consumption by $2036,{ }^{3}$ of which biomass shares the highest fraction in comparison with other renewable energy sources (52.08 and $88.09 \%$ for electricity and heat production, respectively). ${ }^{4}$ According to the Thailand Department of Agriculture Extension (DOAE) report, the amount of agricultural residues generated is $\sim 43$ million $\mathrm{Mg}$ per year. ${ }^{5}$ A large amount of crop residues is also estimated to be generated in other Asian countries, e.g., Vietnam, ${ }^{6}$ Indonesia, ${ }^{7}$ and India $^{7}$ with $\sim 15,55$, and 500 million $\mathrm{Mg}$ per year, respectively. Thus, the utilization of agricultural residues as alternative energy has great potential in Asia.

Rice husk ( $\mathrm{RH})$, a byproduct from the rice milling process, is an agricultural residue generated abundantly in Thailand, $\sim 7.5$ million $\mathrm{Mg}$ per year. ${ }^{8}$ According to Pode, ${ }^{9} 1 \mathrm{Mg}$ of $\mathrm{RH}$ can generate up to $800 \mathrm{~kW}$-h of electricity, which can substitute at least $0.098 \mathrm{Mg}$ of coal. When $\mathrm{RH}$ is used to replace conventional fossil fuels, the $\mathrm{SO}_{x}$ emission would be significantly reduced due to the lower sulfur content of $\mathrm{RH} .{ }^{4}$ Pyrolysis is a promising biomass thermochemical conversion process, and the final products include liquid as bio-oil, solid as biochar, and gas with the presence of light hydrocarbons.

Received: July 21, 2021

Accepted: October 7, 2021

Published: October 20, 2021 


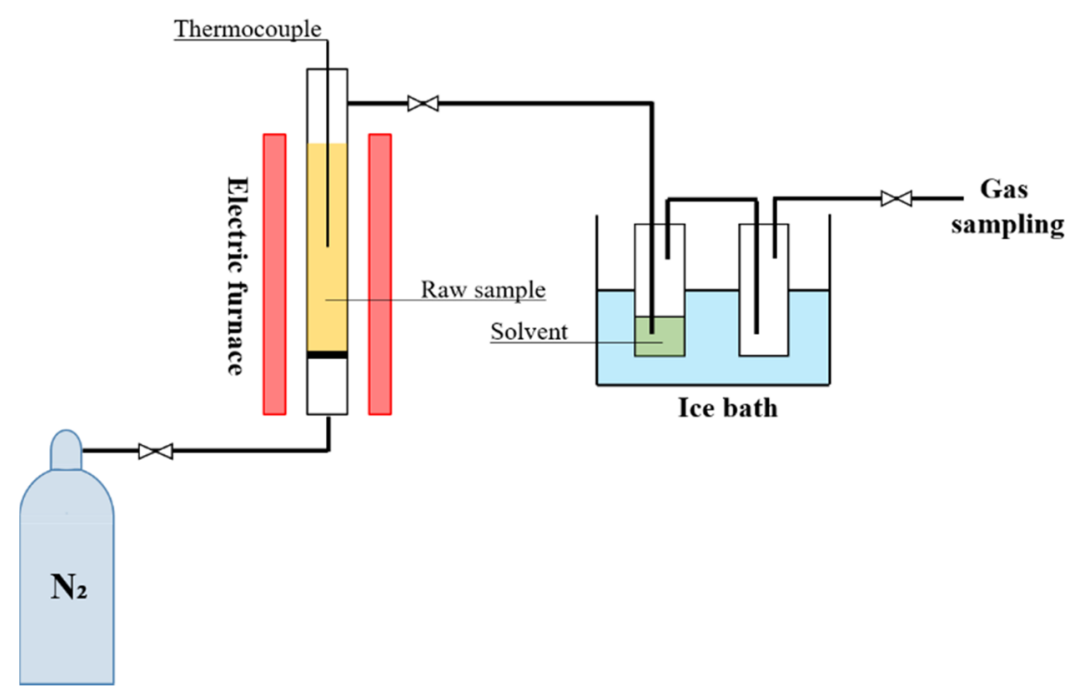

Figure 1. Schematic of the pyrolysis system.

Pyrolysis is generally performed at mid-to-high temperatures under an inert atmosphere (usually nitrogen gas) ${ }^{10}$ and has attracted considerable attention due to its easy-to-operate characteristics, especially in optimizing the yields of targeted products. The products from biomass pyrolysis, however, have lower fuel quality in comparison with conventional fuels. Other types of processing, such as catalytic cracking, hydrotreating, and deoxygenation, can improve or upgrade the pyrolysis products but result in increased operating costs. ${ }^{11}$

A huge amount of plastic waste, $\sim 242$ million tons, was generated in 2016 globally, which primarily came from three regions including East Asia and the Pacific, Europe and Central Asia, and North America. ${ }^{12}$ In Asia, an estimation of 121 million tons of plastic waste was reported in 2016, which accounted for $50 \%$ of the global generation. ${ }^{13}$ According to the United Nations Centre for Regional Development (UNCRD), ${ }^{14}$ Thailand is considered one of the top 11 major polluting countries in the Asia-Pacific region, indicated by the highest mismanagement of plastic waste. Thailand generated $\sim 1.91$ million tons of plastic waste in $2019 .^{15}$ It was ranked in the top five countries with the highest plastic waste generation in 2016, based on the amount of plastic waste generation per capita $(69.54 \mathrm{~kg} /$ year $) .{ }^{16,17}$

Energy recovery can be an option for plastic waste management. Copyrolysis of biomass and plastic is regarded as a promising pathway to obtain products with improved fuel qualities that require no additional processing. Plastics have high carbon $(\mathrm{C})$ and hydrogen $(\mathrm{H})$ content and can serve as a $\mathrm{H}$ donor during copyrolysis. The reaction mechanism of copyrolysis, however, is more complicated in comparison with biomass pyrolysis due to the diversity and heterogeneity of the feedstock. ${ }^{18}$ Although most of the reaction mechanisms in copyrolysis are similar to those in biomass pyrolysis, synergistic effects occur due to the interactions between the different types of species in the feedstocks. ${ }^{19-24}$ These effects may be positive or negative depending on the type of feedstocks and pyrolysis duration and temperature. ${ }^{25}$ Most of the previous copyrolysis studies focus on improving bio-oil production. Tang et al. $^{26}$ reported increased yield and decreased oxygen and water content of bio-oil from copyrolysis of microalgae and low-density polyethylene (LDPE). Similar results were reported in copyrolysis of newspaper and high-density polyethylene (HDPE), where the bio-oil yield increased by 17.50 wt $\%$ when the mass ratio of feedstocks $=1: 1$ as compared to pyrolysis of newspaper alone under the same conditions. The higher heating value (HHV) of the bio-oil from copyrolysis was also comparably higher owing to the decrease of moisture and oxygen contents. ${ }^{27-29}$ The bio-oil yield of the process was also affected by the mass fraction of feedstocks. ${ }^{20}$ Biochar is another value-added product obtained from copyrolysis. Due to the high carbonaceous residue in biochar, the heterogeneous reaction of solid $\mathrm{C}$ with $\mathrm{O}$ is slower than homogeneous oxidation. ${ }^{30}$ Consequently, it is relatively stable compared to bio-oil. Unfortunately, biochar typically has a low heating value ranging between 13.4 and $17.40 \mathrm{MJ} / \mathrm{kg}^{31}$ compared to the heating value of commercial charcoal, which is $\sim 30 \mathrm{MJ} / \mathrm{kg}$. ${ }^{32}$ For this reason, biochar is not attractive for use as an energy resource. The main reason for the low heating value of biochar is that it is inherited from the low heating value properties of the raw biomass itself. Consequently, this work aims to evaluate a feasible method to improve biochar quality through copyrolysis between biomass and a material with a higher heating value such as plastic (41.7-46.4 MJ/ $\mathrm{kg}^{33}$ ). Research on biochar from copyrolysis of biomass and plastic waste, however, is still limited. The present study aims to produce and characterize high-quality biochar through copyrolysis of RH and HDPE. The impacts of plastic fraction and pyrolysis temperature and duration on the yield and physicochemical properties of biochar were investigated. The synergistic effects of $\mathrm{RH}$ and HDPE during copyrolysis were also revealed.

\section{MATERIALS AND METHODS}

2.1. Materials. $\mathrm{RH}$ and recycled HDPE pellet $\left(4 \times 4 \mathrm{~mm}^{2}\right)$ were obtained from a local agricultural area in Maha Sarakham Province, Thailand and Union J. Plus (Thailand) Co., Ltd., respectively. $\mathrm{RH}$ was ground by a blender and then sieved to a particle size range of $0.5-1.0 \mathrm{~mm}$. To break down the polymer chain, the HDPE pellet was initially dissolved in hot toluene at $\sim 110{ }^{\circ} \mathrm{C}$ (the boiling point of toluene is $110.6^{\circ} \mathrm{C}$ ). After the pellet was almost completely dissolved, $\mathrm{RH}$ was added to the plastic-toluene solution. The mixture was stirred to ensure that each rice husk particle was completely wetted by the solution and then air-dried under a hood overnight (described 
in Kositkanawuth et al. ${ }^{34}$ ). The targeted mass fraction of $\mathrm{RH}$ varied from 50 to 90 wt \%.

2.2. Pyrolysis and Copyrolysis Experiments. The pyrolysis tests were conducted using a 316 stainless steel fixed-bed reactor of $600 \mathrm{~mm}$ height and $23.4 \mathrm{~mm}$ inner diameter (i.d.). The reactor was externally heated by a resistance heater connected to a PID temperature controller and K-type thermocouple (Figure 1). A 316 stainless steel tube with $0.4 \mathrm{~mm}$ i.d. was connected to the top of the reactor allowing volatiles to flow into the cold traps containing isopropyl alcohol to collect condensable products. The noncondensable gaseous products were collected in Tedlar gas sampling bags (New Devex bag and PC valve $1 \mathrm{~L}$, HEDETech) at the final outlet. Both pyrolysis and copyrolysis tests were conducted at three temperatures (400, 500, and 600 ${ }^{\circ} \mathrm{C}$ ) and holding periods $(15,30$, and $45 \mathrm{~min})$, with three replicates under each condition (the result was reported as arithmetic mean). About $15 \mathrm{~g}$ of sample was loaded into the reactor and purged with nitrogen gas for $15 \mathrm{~min}$. The reactor was then heated from room temperature to a given temperature at a heating rate of $10{ }^{\circ} \mathrm{C} / \mathrm{min}$ and held for a targeted period. The solid biochar was collected and weighed after cooling the reactor to room temperature. The biochar product was labeled as RHxx-TEMP-TIME, where $\mathrm{xx}$, TEMP, and TIME are the $\mathrm{RH}$ mass fraction, pyrolysis temperature, and hold time, respectively. For instance, RH100-400-15 refers to the biochar obtained from $100 \%$ rice husk pyrolyzed at 400 ${ }^{\circ} \mathrm{C}$ with 15 min holding time.

2.3. Material Characterizations. All samples were dried in an oven at $105 \pm 1{ }^{\circ} \mathrm{C}$ for at least $24 \mathrm{~h}$ before analysis. Proximate, ultimate, and heating value analyses were performed for the raw materials and biochar samples using a LECO TGA801 macro thermogravimetric analyzer, LECO CHN628 elemental analyzer, and LECO AC350 calorimeter (LECO Corp., St. Joseph, MI), respectively. The surface morphologies, surface areas, and chemical structures of four selected biochar samples, i.e., RH100-400-15, RH100-500-15, RH50-400-15, and RH50-500-15, were determined using a JEOL SEM analyzer JSM-6610 LV (JEOL Ltd., Tokyo, Japan), Belsorp mini II BET analyzer (MicrotracBEL Corp., Osaka, Japan), and PerkinElmer KBr FTIR (PerkinElmer Corp., Waltham, MA), respectively. Thermogravimetric analysis (TGA) was conducted using a PerkinElmer Pyris 1 TGA (PerkinElmer Corp., Waltham, MA). About $20 \mathrm{mg}$ of sample was heated from 30 to $900{ }^{\circ} \mathrm{C}$ at a heating rate at $10{ }^{\circ} \mathrm{C} / \mathrm{min}$ under a nitrogen atmosphere for analysis of moisture content (M), volatile matter (VM), and fixed carbon (FC) and under air for analysis of ash (A) $(50.0 \mathrm{~mL} / \mathrm{min}$ gas flow rate) according to ASTM D3172, ${ }^{35} \mathrm{D} 3173,{ }^{36}$ and D3175. ${ }^{37}$

2.4. Data Processing. The biochar yield $(Y)$ was calculated by eq 1 .

$$
\begin{aligned}
Y(w t \%)= & \frac{\text { weight of the product after experiment }(\mathrm{g})}{\text { weight of the original sample }(\mathrm{g})} \\
& \times 100
\end{aligned}
$$

For copyrolysis, the synergistic effect, $\Delta Y$, of RH and HDPE was determined by comparing the differences of product yields between the theoretical and experimental values. Positive and negative values of $\Delta Y$ illustrate positive and negative effects of copyrolysis, respectively. ${ }^{25,27}$

$$
Y_{\text {theo }}=Y_{1} \times W_{1}+Y_{2} \times W_{2}
$$

$$
\Delta Y=Y_{\text {ex }}-Y_{\text {theo }}
$$

where $Y_{\text {theo }}$ and $Y_{\mathrm{ex}}$ are the theoretical and experimental biochar yields, respectively, and $Y$ and $W$ are the experimental biochar yield and the mass fraction of each feedstock.

The energy yield $\left(\eta_{\mathrm{E}}\right)$ and fixed carbon yield $\left(Y_{\mathrm{fc}}\right)$ were calculated using the following equations as indicators of process performance.

$$
\begin{aligned}
& \text { energy yield }\left(\eta_{\mathrm{E}}\right)=Y \times\left(\frac{\mathrm{HHV}_{\mathrm{bc}}}{\mathrm{HHV}_{\mathrm{o}}}\right)_{\mathrm{dry}} \\
& \text { fixed carbon yield }\left(Y_{\mathrm{fc}}\right)=Y \times\left(\frac{\mathrm{FC}}{100-\text { feed ash }}\right)_{\mathrm{dry}}
\end{aligned}
$$

where $H H V_{o}$ and $H H V_{b c}$ are the higher heating values $(\mathrm{MJ} /$ $\mathrm{kg}$ ) of the feedstock and the corresponding biochar product, respectively, and FC (\%) is the fixed carbon content of the

\begin{tabular}{|c|c|c|}
\hline & $\mathrm{RH}$ & HDPE \\
\hline \multicolumn{3}{|c|}{ proximate analysis (wt \%, ar) } \\
\hline moisture & $7.04 \pm 0.02$ & $0.22 \pm 0.04$ \\
\hline volatile & $61.70 \pm 0.74$ & $97.14 \pm 0.52$ \\
\hline fixed carbon & $15.31 \pm 2.21$ & $0.00 \pm 0.00$ \\
\hline ash & $15.95 \pm 1.47$ & $2.64 \pm 0.25$ \\
\hline \multicolumn{3}{|c|}{ ultimate analysis (wt \%, daf) } \\
\hline $\mathrm{C}$ & $46.75 \pm 0.64$ & $83.69 \pm 0.45$ \\
\hline $\mathrm{H}$ & $6.66 \pm 0.11$ & $15.23 \pm 0.25$ \\
\hline $\mathrm{N}$ & $0.66 \pm 0.15$ & $0.21 \pm 0.01$ \\
\hline $\mathrm{O}(\mathrm{diff})^{b}$ & 45.94 & 0.88 \\
\hline $\mathrm{O} / \mathrm{C}$ & 0.74 & 0.01 \\
\hline $\mathrm{H} / \mathrm{C}$ & 1.71 & 2.18 \\
\hline \multicolumn{3}{|c|}{ higher heating value $\left(\mathrm{MJ} \cdot \mathrm{kg}^{-1}, \mathrm{db}\right)$} \\
\hline & $15.59 \pm 0.02$ & $43.89 \pm 0.10$ \\
\hline
\end{tabular}
biochar product.

\section{RESULTS AND DISCUSSION}

3.1. Raw Material Characterizations. Table 1 illustrates the results of proximate and ultimate analyses of raw $\mathrm{RH}$ and

Table 1. Physicochemical Properties of the Feedstock ${ }^{a}$

HDPE. The thermogravimetric (TG) and derivative thermogravimetric (DTG) curves of the samples under a nitrogen atmosphere are shown in Figure 2 and exhibit significantly different thermal behaviors owing to their composition differences. RH mass loss behavior is similar to other biomass materials, as it is mainly comprised of cellulose, hemicellulose, and lignin (Figure 2A). The decomposition of $\mathrm{RH}$ primarily occurs between 240 and $400{ }^{\circ} \mathrm{C}$, with a maximum mass loss rate of $1.80 \% / \mathrm{min}$ at $316^{\circ} \mathrm{C}$ (Figure $2 \mathrm{~B}$ ). The shoulders of the DTG curve $\left(202-345.5{ }^{\circ} \mathrm{C}\right)$ indicate simultaneous degradation of cellulose and hemicellulose decomposition, ${ }^{38}$ and the mass loss after $400{ }^{\circ} \mathrm{C}$ is associated with lignin degradation and material carbonization. ${ }^{39}$ In contrast, the thermal decomposition of HDPE only has a single sharp peak $\left(398-473{ }^{\circ} \mathrm{C}\right)$ with a maximum mass loss rate of $6.47 \% / \mathrm{min}$ at $443{ }^{\circ} \mathrm{C}$, which is similar to the reported values, $398-474{ }^{\circ} \mathrm{C} .{ }^{38,40,41}$ The decomposition of HDPE starts at a temperature, $398{ }^{\circ} \mathrm{C}$, at which the $\mathrm{RH}$ already lost 57.38 wt \% mass. As HDPE is mainly polymerized ethylene, only $\sim 2.15$ wt $\%$ remains as 

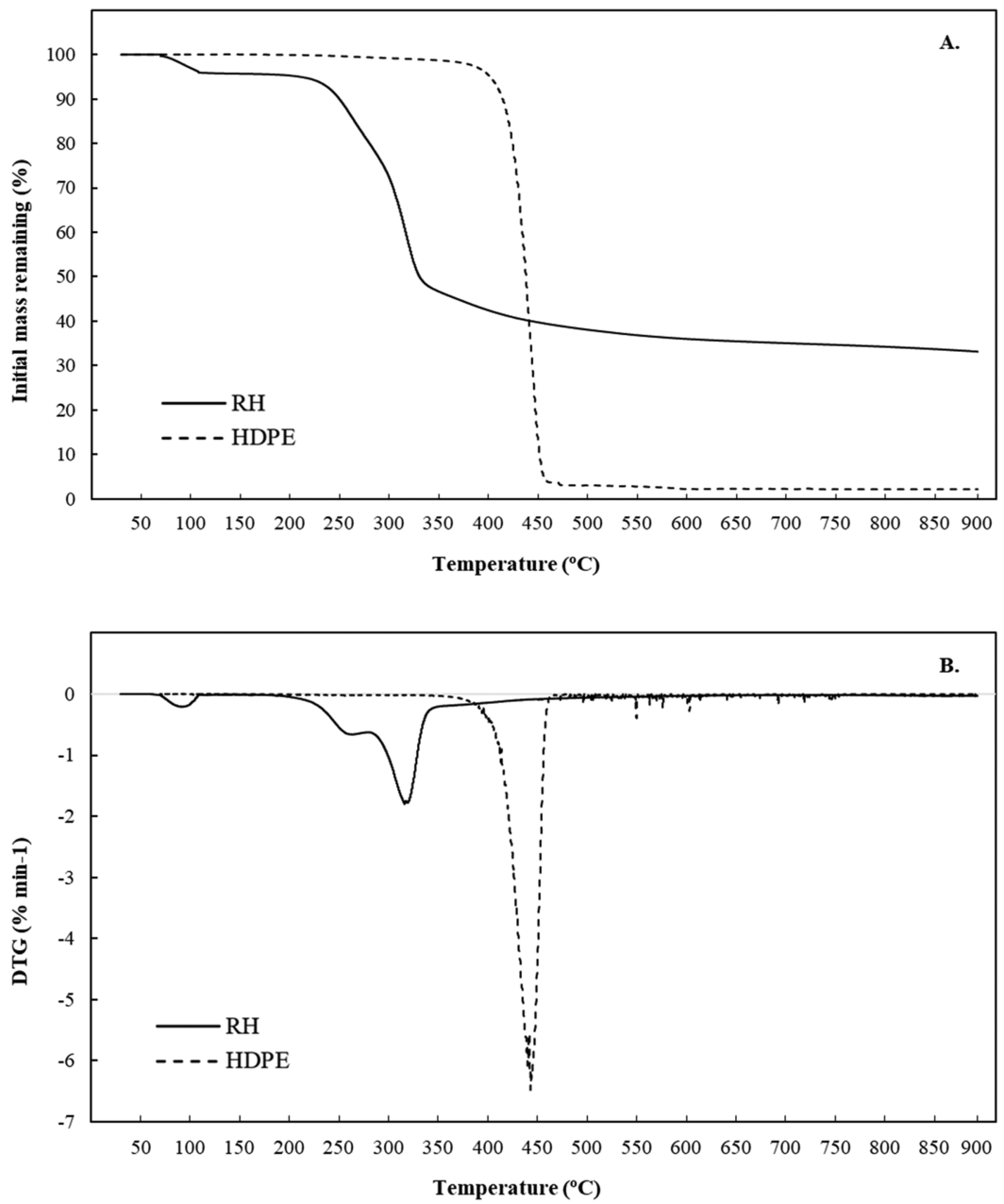

Figure 2. TG (A) and DTG (B) curves of raw RH and HDPE under a nitrogen atmosphere at a $10{ }^{\circ} \mathrm{C} / \mathrm{min}$ heating rate.

residue at $900{ }^{\circ} \mathrm{C}$, whereas the value for $\mathrm{RH}$ is 33.19 wt \% due to its high ash content $(\sim 16 \%)$ and more complex molecular structure.

3.2. Biochar Yields. 3.2.1. Pyrolysis of $R H$. Figure 3 displays the yields of biochar from $\mathrm{RH}$ pyrolysis under

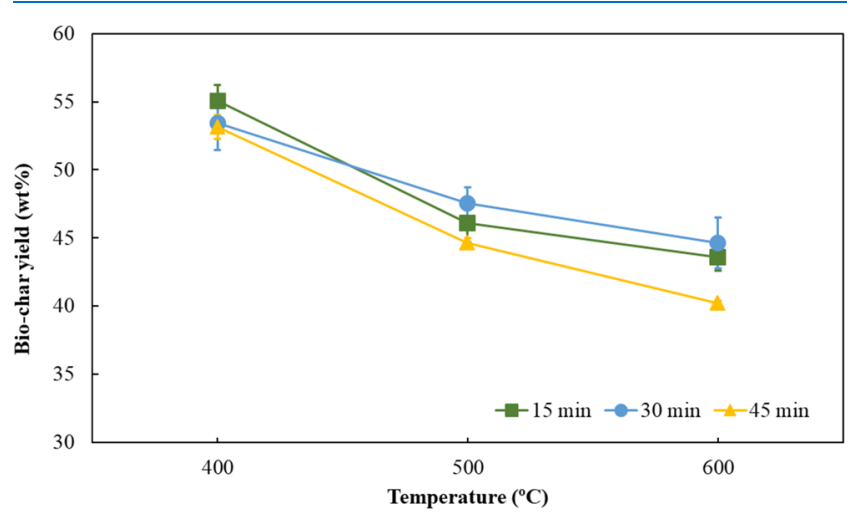

Figure 3. Individual RH biochar yields.

different operating conditions. As expected, the biochar yields decrease with an increase of pyrolysis temperature, as the higher temperature usually leads to increased cracking of organic constituents of biomass. ${ }^{42}$ The biochar yield at $400{ }^{\circ} \mathrm{C}$, 53.14-55.06 wt \%, is higher than those obtained at 500 and
$600{ }^{\circ} \mathrm{C}, 47.54$ and 40.20 wt \%, respectively. This may result from the secondary decomposition of the biochar or biomass under elevated temperature conditions, $400-600{ }^{\circ} \mathrm{C}$. ${ }^{43}$ The temperature has less impact on the yield when increased from 500 to $600{ }^{\circ} \mathrm{C}$, as the major fraction of hemicellulose and cellulose and part of the lignin already degraded when the temperature reaches $500{ }^{\circ} \mathrm{C}$. This is also demonstrated by the TGA analysis, i.e., no significant mass loss after $500{ }^{\circ} \mathrm{C}$.

The holding time exhibits only minor impacts in the biochar yield, i.e., the change of yields is not significant when the holding time was extended from 15 to $45 \mathrm{~min}$. Approximately 3 wt \% decreases of biochar yield were observed in RH100-500 and RH100-600 tests when the holding time was increased from 30 to $45 \mathrm{~min}$. Theoretically, the degradation of the feedstock increases with the holding time. ${ }^{44,43}$ The TG curves in Figure $2 \mathrm{~A}$ exhibit limited mass loss above $450{ }^{\circ} \mathrm{C}$, and this could be thought to equate to extended hold time as the temperature increases for an additional $40 \mathrm{~min}$ from 500 to $900{ }^{\circ} \mathrm{C}$

3.2.2. Copyrolysis of $R H$ and HDPE. The temperature and holding time have similar impacts on biochar yields as those of $\mathrm{RH}$ pyrolysis for copyrolysis of RH and HDPE. Thus, the mass fraction of HDPE becomes the dominant factor in biochar yields (Figure 4). As the biochar yield from 15 min holding is similar to that from 30 and $45 \mathrm{~min}$, only data obtained from 15 min are included in Figure 4. Overall, different trends are observed for copyrolysis temperatures of 400 and $500 / 600{ }^{\circ} \mathrm{C}$. 


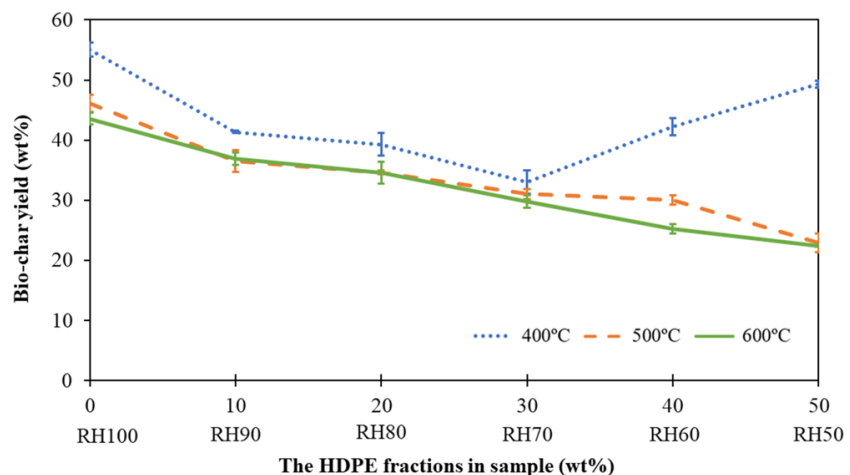

Figure 4. Experimental biochar yields at a constant holding time of 15 min (Figures S1 and S2 refer to the experimental biochar yields at constant holding times of 30 and $45 \mathrm{~min}$, respectively).

The increase of HDPE mass fraction initially results in decreased biochar yields when the pyrolysis temperature is at $400{ }^{\circ} \mathrm{C}$, i.e., the yield decreases from 41.36 to $33.02 \mathrm{wt} \%$ when the HDPE mass fraction increased from 10 to $30 \mathrm{wt} \%$ (RH90 to RH70). The yields, however, increase to 42.24 and $49.29 \mathrm{wt}$ $\%$ when the HDPE fraction is 40 and 50 wt \%, respectively, which may result from the incomplete degradation/reaction of HDPE, as the pyrolysis temperature is not high enough. Similar results were reported by Caglar and Aydinli ${ }^{46}$ that a wax of ultrahigh-molecular-weight polyethylene (UHMWPE) formed inside the reactor when copyrolysis was conducted with hazelnut shell and UHMWPE at $425{ }^{\circ} \mathrm{C}$, which was lower than the maximum decomposition temperature of UHMPE, $485{ }^{\circ} \mathrm{C}$. In addition, the incomplete degradation of HDPE is also demonstrated by the proximate analysis, i.e., the volatile matter contents of the solid products obtained at $400{ }^{\circ} \mathrm{C}$ using RH60 and RH50 feedstocks are both $>50 \mathrm{wt} \%$. The increased yield of solids is associated with the melting of HDPE and $\mathrm{RH}$ is coated by melted HDPE, which possibly hinders the escape of VM from the RH and leads to coking. ${ }^{47}$

Opposite trends are observed when the copyrolysis temperature is at 500 and $600{ }^{\circ} \mathrm{C}$. A lower solid yield is obtained from feedstock with a lower RH content, as most HDPE in the sample already evaporated when the temperature went beyond its main decomposition temperature (at $\sim 474{ }^{\circ} \mathrm{C}$ according to TGA in this study). When the HDPE mass fraction increased from 10 to 50 wt \%, the biochar yields decreased from 36.53 to 22.91 wt $\%$ at $500{ }^{\circ} \mathrm{C}$ and from 36.95 to 22.42 wt $\%$ at $600{ }^{\circ} \mathrm{C}$. Similar results were also reported by Caglar and Aydinli ${ }^{46}$ on copyrolysis of hazelnut and UHMWPE at different weight ratios. With an increase of plastic fraction, the solid yield decreased from 26.0 to 5.0 wt $\%$ at $515{ }^{\circ} \mathrm{C}$. ${ }^{46}$ The yields of gasphase products also increased with an increase of plastic fraction and pyrolysis temperature, resulting in a lower char yield. Abnisa et al. ${ }^{48}$ quantified bio-oil production from copyrolysis of palm shell and PS with different ratios (PS decomposition temperature $>350{ }^{\circ} \mathrm{C}^{49}$ ) and found that oil yield continuously increased from $\sim 45$ to $>60$ wt \% with an increase of PS fraction from 20 to $60 \mathrm{wt} \%$ at $400{ }^{\circ} \mathrm{C}$, whereas the char yield decreased from $\sim 27$ to 14 wt $\%$.

3.2.3. Synergistic Effects. The difference in theoretical and experimental yields, $\Delta Y$, is used to evaluate the synergistic effect of mixing the RH and HDPE (Figure 5). The copyrolysis generally exhibits negative impacts on biochar production, as indicated by the negative values of $\Delta Y$. As the primary target of copyrolysis is to improve the yield and quality of bio-

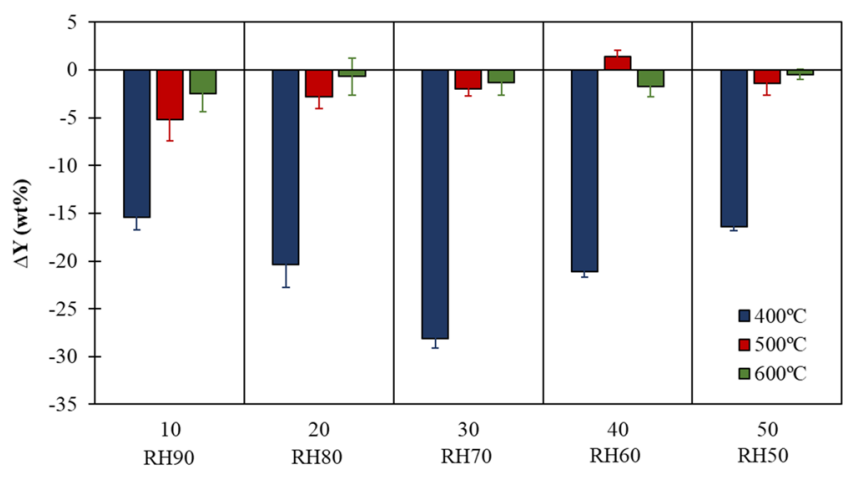

The HDPE fractions in sample (wt \%)

Figure 5. Differences between theoretical and experimental biochar yields $(\Delta Y)$ from copyrolysis under a constant holding time of $15 \mathrm{~min}$ (Figures S3 and S4 refer to differences between theoretical and experimental biochar yields $(\Delta Y)$ from copyrolysis under constant holding times of 30 and $45 \mathrm{~min}$, respectively).

oil, $^{26,27,29,50-52}$ the negative synergistic effect on biochar production can be attributed to the interaction between biomass and polymer that tends to produce more volatile products. The free radicals derived from $\mathrm{RH}$ decomposition initially promote the degradation of HDPE and the formation of hydrocarbon radicals. This interaction involves initiation and secondary radical formation via depolymerization, $\mathrm{H}$ transfer, and reaction between radicals. ${ }^{38,53}$ Similar results were reported by Chen et al. $^{54}$ on the copyrolysis of waste newspaper (WP) and HDPE, and the negative synergistic effects on biochar production were observed.

The $\Delta Y$ at $400{ }^{\circ} \mathrm{C}$ is much lower than that at 500 and 600 ${ }^{\circ} \mathrm{C}$, indicating that the impact of radical interaction on solid product yields is much less when the copyrolysis temperature exceeds the HDPE decomposition temperature. $\Delta \mathrm{Y}$ is found to decrease with an increase of HDPE mass fraction, reach the minimum value with $\mathrm{RH} 70$, and then increase with the HDPE fraction for RH60 and RH50 when the copyrolysis temperature is at $400{ }^{\circ} \mathrm{C}$. This may relate to both the heat transfer in the reactor and the interactions between RH and HDPE radicals. As higher plastic ratios can cause more agglomeration of particles in the blended samples, the heat transfer across the entire sample becomes poor. Furthermore, the amount of free radicals generates from $\mathrm{RH}$ decomposition for activating the HDPE degradation decreases with the $\mathrm{RH}$ fraction in the samples, resulting in the incomplete conversion of HDPE in RH60 and RH50 samples at $400{ }^{\circ} \mathrm{C}$. Activated hydrocarbon radicals may also react with the free radicals from $\mathrm{RH}$ and form stable species, which are then adsorbed on the $\mathrm{RH}$ residue, ${ }^{55}$ leading to a slight increase in $\Delta Y$ values.

3.3. Biochar Characterizations. 3.3.1. Proximate, Ultimate, and HHV Analyses. The results from proximate, ultimate, and HHV analyses for both individual and blended biochars are illustrated in Figures 6 and 7 and listed in Table 2. As the influences of temperature and holding time on $\mathrm{RH}$ biochars (RH) and copyrolysis biochars (RH50 to RH90) are relatively similar, they are discussed together. The impacts of feedstock ratios are discussed separately.

The VM contents are greatly decreased from 25.46-26.64 to 7.01-9.57 wt \% in RH biochars and from 8.57-65.21 to 4.3519.53 wt \% in blended biochars when the pyrolysis temperature increases from 400 to $600{ }^{\circ} \mathrm{C}$. More volatiles and gases are released under high-temperature conditions, 

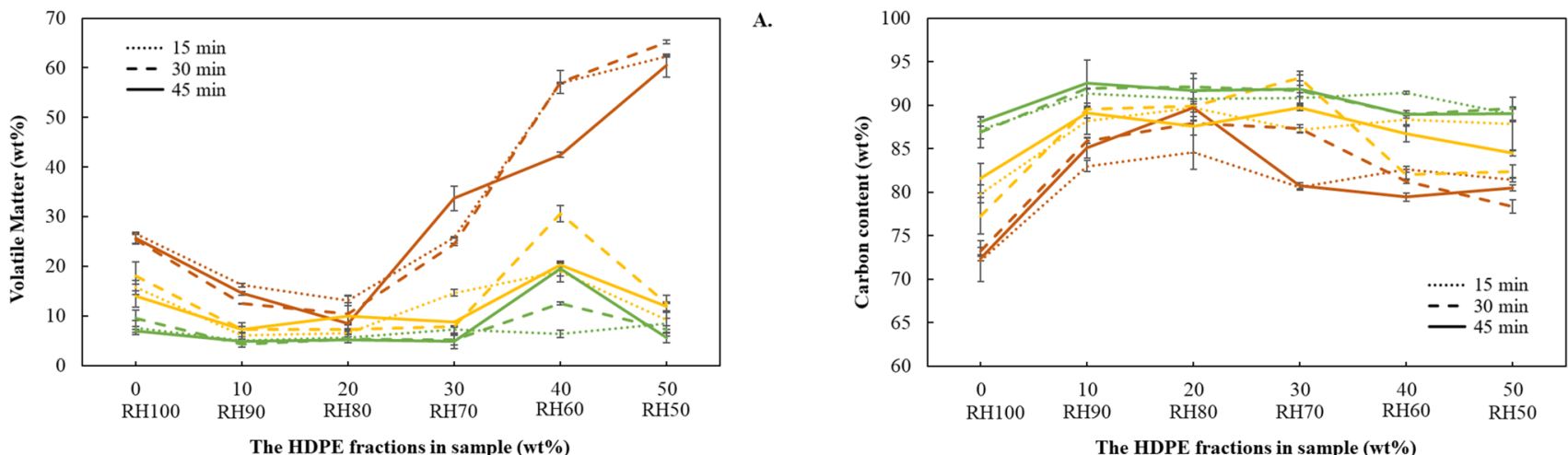

A.
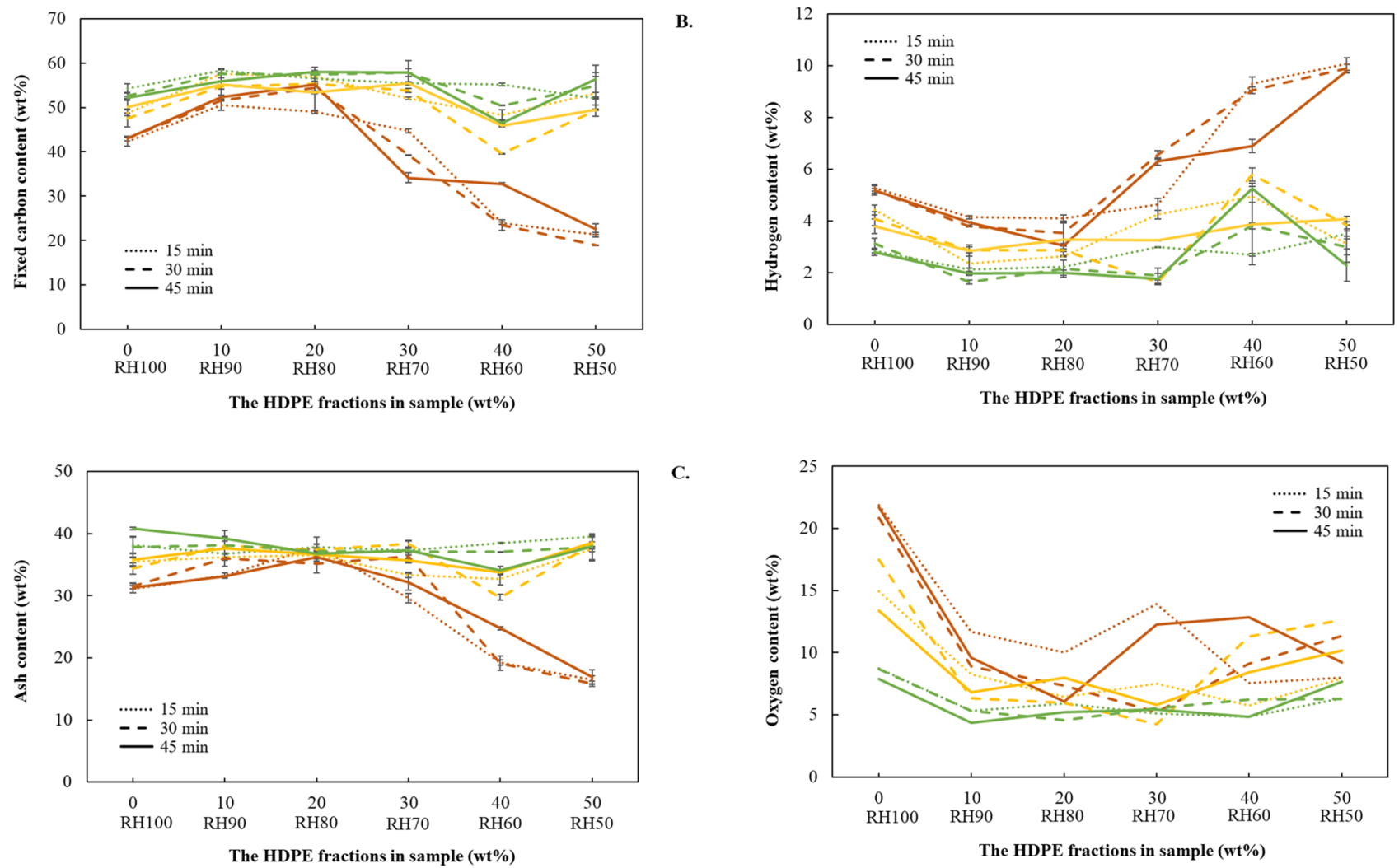

Figure 6. Proximate compositions in $\mathrm{RH}$ and blended biochars obtained at different conditions: (A) volatile matter, (B) fixed carbon, (C) ash (orange lines represent biochars produced at $400{ }^{\circ} \mathrm{C}$, yellow lines represent biochars produced at $500{ }^{\circ} \mathrm{C}$, and green lines represent biochars produced at $600{ }^{\circ} \mathrm{C}$ ).

resulting in increases of FC (from 42.27-43.03 to 52.1854.27 wt \% in RH biochars and from 18.95-55.21 to 46.4458.23 wt \% in blended biochars) and ash (from 31.08-31.53 to $37.84-40.81$ wt \% in $\mathrm{RH}$ biochars and from $15.85-37.95$ to 34.04-39.50 wt \% in blended biochars) contents. The changes in product compositions are associated with the decompositions of hemicellulose, cellulose, and some lignin in raw $\mathrm{RH}^{56}$ Further decomposition of the lignocellulosic structure would be responsible for a lower VM content at $600{ }^{\circ} \mathrm{C},{ }^{57}$ and FC is gradually formed through volatilization, char rearrangement, and deactivation reactions. ${ }^{58}$

Small changes in RH proximate analysis results are observed for different holding times $(<4 \%$ absolute $)$ at the same pyrolysis temperature. The impacts of holding time, however, are more significant for blended biochars, especially when the

Figure 7. Elemental compositions in $\mathrm{RH}$ and blended biochars obtained at different conditions: (A) carbon, (B) hydrogen, and (C) oxygen (orange lines represent biochars produced at $400{ }^{\circ} \mathrm{C}$, yellow lines represent biochars produced at $500{ }^{\circ} \mathrm{C}$, and green lines represent biochars produced at $600{ }^{\circ} \mathrm{C}$ ).

plastic fraction is high. For instance, more than 8 and 6 wt \% changes in combustible fractions (i.e., VM and FC) of RH60 biochars produced at $500{ }^{\circ} \mathrm{C}$ are observed when the holding time is extended from 15 to 30 and 30 to $45 \mathrm{~min}$, respectively. A longer holding time generally diminishes the amount of solid product via secondary biochar cracking, leading to changes in their proximate compositions. ${ }^{44,45}$ Moreover, Ronsse et al. ${ }^{59}$ and Pecha and Garcia-Perez ${ }^{60}$ reported that the primary volatile products can be further cracked or repolymerized via secondary reactions if the vapor holding time is more than $1 \mathrm{~s}$. Thus, more vapor phase homogeneous reactions occurred with an increased holding time, i.e., a longer holding time provided more chances for the hot biochar to react with volatile products generated. ${ }^{61}$ Although temperature and holding time 
Table 2. Higher Heating Value (HHV) for the Biochar Produced in This Study

\begin{tabular}{|c|c|c|c|c|c|c|}
\hline \multirow[b]{2}{*}{ temperature $\left({ }^{\circ} \mathrm{C}\right)$} & \multicolumn{6}{|c|}{$\mathrm{HHV}(\mathrm{MJ} / \mathrm{kg})$} \\
\hline & RH100 & RH90 & RH80 & RH70 & RH60 & RH50 \\
\hline \multicolumn{7}{|c|}{ Holding Time of $15 \mathrm{~min}$} \\
\hline 400 & $19.38 \pm 0.39$ & $20.95 \pm 0.21$ & $21.92 \pm 2.88$ & $21.21 \pm 0.18$ & $28.87 \pm 0.92$ & $30.01 \pm 3.00$ \\
\hline 500 & $19.44 \pm 0.43$ & $20.68 \pm 0.52$ & $19.78 \pm 0.17$ & $20.95 \pm 0.11$ & $22.95 \pm 0.86$ & $20.62 \pm 0.79$ \\
\hline 600 & $20.27 \pm 0.47$ & $19.86 \pm 0.42$ & $20.18 \pm 0.11$ & $20.57 \pm 0.30$ & $18.90 \pm 0.41$ & $19.56 \pm 0.27$ \\
\hline \multicolumn{7}{|c|}{ Holding Time of $30 \mathrm{~min}$} \\
\hline 400 & $19.48 \pm 0.26$ & $20.66 \pm 0.42$ & $20.86 \pm 1.77$ & $22.29 \pm 1.53$ & $28.32 \pm 0.81$ & $31.40 \pm 2.28$ \\
\hline 500 & $19.65 \pm 0.65$ & $19.88 \pm 0.57$ & $20.00 \pm 0.17$ & $20.07 \pm 0.17$ & $21.41 \pm 0.76$ & $19.17 \pm 0.61$ \\
\hline 600 & $20.19 \pm 0.22$ & $19.58 \pm 0.18$ & $20.55 \pm 0.00$ & $20.22 \pm 0.38$ & $20.15 \pm 0.35$ & $20.21 \pm 0.23$ \\
\hline \multicolumn{7}{|c|}{ Holding Time of $45 \mathrm{~min}$} \\
\hline 400 & $19.10 \pm 0.36$ & $21.55 \pm 0.37$ & $19.86 \pm 2.02$ & $19.47 \pm 1.19$ & $26.52 \pm 1.98$ & $30.70 \pm 1.88$ \\
\hline 500 & $19.41 \pm 0.27$ & $19.83 \pm 0.47$ & $19.95 \pm 0.28$ & $20.03 \pm 0.20$ & $21.18 \pm 0.83$ & $19.41 \pm 0.54$ \\
\hline 600 & $19.88 \pm 0.11$ & $18.75 \pm 0.28$ & $20.30 \pm 0.25$ & $19.87 \pm 0.38$ & $20.62 \pm 0.27$ & $19.63 \pm 0.09$ \\
\hline
\end{tabular}

both influence proximate analysis of biochars, the temperature has more significant impacts.

There is a significant improvement in the $\mathrm{C}$ content of all biochars as compared to that of raw RH. A slow pyrolysis process mainly induces bond breaking between $\mathrm{C}$ and functional groups on the biomass surface, such as $-\mathrm{OH}$, aliphatic $\mathrm{C}-\mathrm{O}$, and aliphatic $\mathrm{C}-\mathrm{H}$ groups. ${ }^{62}$ Thus, an increase in $\mathrm{C}$ content in the solid products is expected from the pyrolysis process. The $\mathrm{C}$ content of the $\mathrm{RH}$ biochars produced at $400{ }^{\circ} \mathrm{C}$ is $\sim 1.5$ times higher than that of the original $\mathrm{RH}$ under all holding times. When the temperature increases from 400 to $600{ }^{\circ} \mathrm{C}$, the $\mathrm{C}$ content increases from $\sim 70$ to $\sim 80$ wt \% for $\mathrm{RH}$ biochars and $\sim 80$ to 88 wt $\%$ for blended biochars. A maximum of 6.78 wt \% increase of $\mathrm{C}$ content can be achieved by increasing the holding time. Besides, the decrease of $\mathrm{H}$ and O contents is observed. Similar to biochar yields, the holding time seems to have less impact on the biochar element compositions than temperature. The $\mathrm{C}$ content is in a range of other agricultural biochar products, i.e., empty fruit bunch, corncob, oak slabs, and Leucaena wood, 60 and 95 wt \%. ${ }^{63,64}$

Table 2 presents the sample HHV data. Values increase from $\sim 14 \mathrm{MJ} / \mathrm{kg}$ for raw $\mathrm{RH}$ to $19-20 \mathrm{MJ} / \mathrm{kg}$ for $\mathrm{RH}$ biochars and 19-31 MJ/kg for blended biochars. Ang1n ${ }^{65}$ suggested that $\mathrm{HHV}$ in biomass is typically upgraded as a function of pyrolysis temperature. No significant changes of $\mathrm{HHV}$ are observed with temperature change for $\mathrm{RH}$ biochars, whereas the HHV of blended biochars with the highest HDPE blending rates decreases by $\sim 36 \%$ (relative) when the temperature increases from 400 to $600{ }^{\circ} \mathrm{C}$. The holding time is found to have less influence on the HHV of biochars.

The feedstock ratio is the dominant factor in copyrolysis. Two different trends are observed from proximate analysis at $400{ }^{\circ} \mathrm{C}$ and at $500 / 600{ }^{\circ} \mathrm{C}$ when HDPE is added. At $400{ }^{\circ} \mathrm{C}$, VM sharply increases from 16.25 to 66.28 wt \% when the HDPE ratio increased from 10 to 50 wt \% (RH90 to RH50), resulting in a decrease in FC and ash content. As the ash content of HDPE is almost 0 wt \%, a higher HDPE fraction in feedstock leads to a lower ash content in the final biochars. At 500 and $600{ }^{\circ} \mathrm{C}$, fewer variations in VM (between 5.06 and 14.65 wt \%), FC (between 52.04 and 58.23 wt \%), and ash content (between 33.31 and 37.83 wt \%) are observed, except for the feedstocks with high plastic ratios, i.e., RH60 and RH50.

The addition of HDPE noticeably affects the elemental composition of biochar. In comparison with the $\mathrm{RH}$ biochars obtained under the same conditions, an increased $\mathrm{C}$ content (i.e., 5.14-17.29, 2.90-15.82, and 0.85-5.22 wt \%) and a decreased $O$ content (i.e., 7.97-15.66, 3.19-13.23, and 0.244.13 wt \%) are observed in blended biochars obtained at 400, 500 , and $600{ }^{\circ} \mathrm{C}$, respectively. Changes in the $\mathrm{H}$ content depend on the HDPE fraction in the raw samples. An increase in the HDPE fraction from 0 to 20 and $30 \mathrm{wt} \%$ results in an increased $\mathrm{C}$ content of the blended biochar pyrolyzed at 400 and $500 / 600{ }^{\circ} \mathrm{C}$. The $\mathrm{C}$ content then reduces due to the further increase of HDPE fraction (i.e., RH60-500-15 = 88.37 wt \% C; RH50-500-15 = 87.85 wt \% C). An opposite trend, however, is observed for the $\mathrm{H}$ content, except for a sharp reduction of the $\mathrm{H}$ content of the blended biochar obtained at 500 and $600{ }^{\circ} \mathrm{C}$ (i.e., RH60-500-15 = 4.94 wt \% H; RH50-500$15=3.11 \mathrm{wt} \% \mathrm{H}$ ) when the HDPE fraction increased from 40 to $50 \mathrm{wt} \%$. One possible explanation for the reduction in the $\mathrm{H}$ content would be the interaction between plastic materials and hot biochars, releasing more $\mathrm{H}$ into gas-phase products such as $\mathrm{CH}_{4}$ and $\mathrm{H}_{2}$, resulting in a lower $\mathrm{H}$ content. Similar results were reported by Chen et al., ${ }^{54}$ wherein a 4.81 wt \% (absolute) increase in C (59.00-63.81 wt \%) and a 5.1 wt \% (absolute) decrease in $\mathrm{O}(38.88-33.78$ wt \%) due to the addition of 50 wt \% HDPE in newspaper waste for copyrolysis were found. The improvement in biochar quality may associate with the presence of reactive $\mathrm{H}$, transferring from polyethylene chains to $\mathrm{RH}$-derived radicals, resulting in secondary cracking of RH-derived biochar. ${ }^{66}$ The addition of 10 wt \% HDPE leads to a sharp reduction of the $\mathrm{O}$ content, resulting in an increase in $\mathrm{C}$ content. No significant change in the $\mathrm{O}$ content is observed for the feedstocks with higher HDPE contents (2050 wt \%).

It is worth noting that the HDPE fraction has more significant impacts on proximate and ultimate analysis results at $400{ }^{\circ} \mathrm{C}$ rather than that at 500 and $600{ }^{\circ} \mathrm{C}$, at which HDPE decomposition is completed, as the decomposition of HDPE begins at $400^{\circ} \mathrm{C}$. Incomplete degradation of HDPE is observed at $400{ }^{\circ} \mathrm{C}, \sim 25$ wt $\% \mathrm{HPDE}$ is degraded. A higher plastic fraction can result in agglomeration of particles inside the reactor and hinder the heat transfer across the entire sample, as the heat flow is influenced by the particle size and heterogeneity of samples and pyrolysis products. ${ }^{67}$ Less variation of chemical composition, therefore, is observed at 500 and $600{ }^{\circ} \mathrm{C}$, as HDPE is mostly volatilized.

To assess the graphitization and aromatization of the biochar products, their $\mathrm{H} / \mathrm{C}$ and $\mathrm{O} / \mathrm{C}$ ratios are compared to other conventional solid fuels on a van Krevelen diagram (Figure 8). In comparison with raw $\mathrm{RH}(\mathrm{O} / \mathrm{C}=0.74)$, the $\mathrm{O} / \mathrm{C}$ values for 


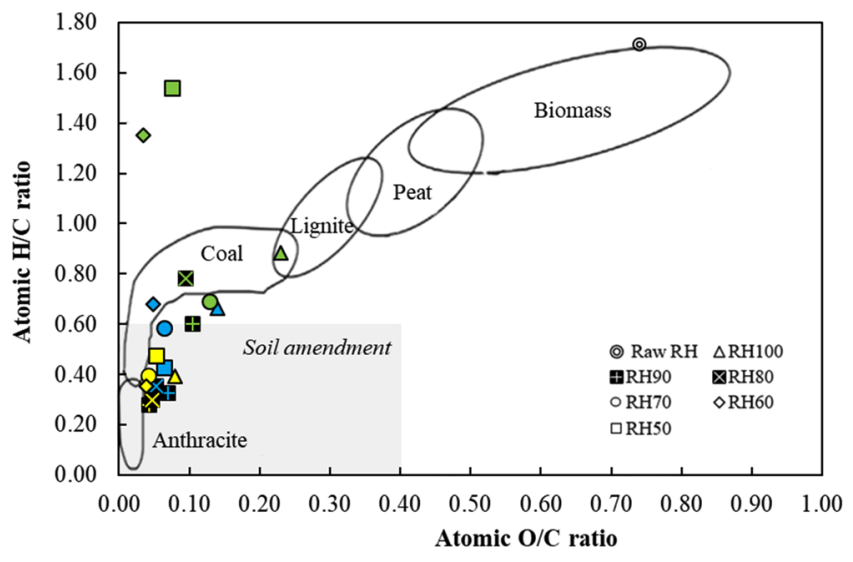

Figure 8. van Krevelen diagram for biochar productions under a constant holding time of $15 \mathrm{~min}$ (green markers represent biochars produced at $400{ }^{\circ} \mathrm{C}$, blue markers represent biochars produced at 500 ${ }^{\circ} \mathrm{C}$, and yellow markers represent biochars produced at $600{ }^{\circ} \mathrm{C}$ ) (Figures S5 and S6 refer to van Krevelen diagrams for biochar productions under constant holding times of 30 and $45 \mathrm{~min}$, respectively).

both individual and blended biochars are quite low, ranging between 0.07 and 0.23 for RH biochars and 0.03 and 0.13 for blended biochars, and the value tends to decrease with an increase of pyrolysis temperature. The decrease in $\mathrm{O} / \mathrm{C}$ indicates a higher degree of carbonization owing to the removal of hydrophilic functional groups from original $\mathrm{RH}$ feedstock structures. ${ }^{68} \mathrm{~A}$ different trend of the $\mathrm{O} / \mathrm{C}$ ratio is observed at high HDPE ratios (RH60 and RH50). The O/C ratio first increases slightly and then decreases with the change in the temperature from 400 to $500{ }^{\circ} \mathrm{C}$ and then 500 to 600 ${ }^{\circ} \mathrm{C}$, respectively.

Similarly, $\mathrm{H} / \mathrm{C}$ decreases as the temperatures increase from raw $\mathrm{RH}(\mathrm{H} / \mathrm{C}=1.71)$ to $\mathrm{RH}$ biochars $(\mathrm{H} / \mathrm{C}=0.38-0.88)$ and blended biochars $(\mathrm{H} / \mathrm{C}=0.28-1.54)$. A reduction in the $\mathrm{H} / \mathrm{C}$ ratio usually indicates higher structural stability in biochar due to the increase in aromaticity. ${ }^{69}$ Similar results were reported by Kaewtrakulchai et al. ${ }^{70}$ on the influences of temperature on fuel characteristics of biochars obtained from corn stalk, pineapple residue, and cassava cake, in which $\mathrm{H} / \mathrm{C}$ and $\mathrm{O} / \mathrm{C}$ were found to decrease from $0.61-0.80$ to $0.38-0.43$ and $0.22-0.30$ to $0.14-0.16$, respectively, with an increase of pyrolysis temperature from 400 to $600{ }^{\circ} \mathrm{C}$. Overall, variations in $\mathrm{H} / \mathrm{C}$ and $\mathrm{O} / \mathrm{C}$ among biochar samples decrease under higher reaction temperatures, indicating that aromaticity and polarity in biochars become more homogeneous through dehydration and decarboxylation reactions. ${ }^{71}$

Biomass loses more $\mathrm{O}$ and $\mathrm{H}$ than $\mathrm{C}$ in the pyrolysis process (Figure 8). The changes in biochar properties, therefore, are associated with an increase of $\mathrm{C}$ content, resulting in an increase of HHV and the energy density of the biochar produced. ${ }^{72}$ The $\mathrm{H} / \mathrm{C}$ and $\mathrm{O} / \mathrm{C}$ of most biochars obtained in this study are close to coal and anthracite, especially for those obtained at 500 and $600{ }^{\circ} \mathrm{C}$. This is consistent with the results obtained from the proximate analysis, i.e., higher temperatures leading to more aromatization, especially when the temperature is $>400{ }^{\circ} \mathrm{C}$, as the release of VM promotes aromatization. ${ }^{62}$ Similarly, Kaewtrakulchai et al. ${ }^{70}$ also reported that chemical structures of biochars generated from higher temperatures are closer to that of natural coal.

Note that $\mathrm{H} / \mathrm{C}$ and $\mathrm{O} / \mathrm{C}$ ratios of biochars produced at 400 ${ }^{\circ} \mathrm{C}$ are moderately improved. These ratios fall between those of lignite and coal for $\mathrm{RH}$ biochars. The $\mathrm{H} / \mathrm{C}$ ratios of $\mathrm{RH} 90$, $\mathrm{RH} 80$, and $\mathrm{RH} 70$ biochars are close to those of coal and anthracite, whereas the RH60 and RH50 biochars are comparable to the broader range of coal types, indicating that copyrolysis improves biochar when plastic addition is $<40$ wt $\%$, especially at low temperatures, i.e., $<400{ }^{\circ} \mathrm{C}$. For other applications, Schimmelpfennig and Glaser ${ }^{73}$ suggested that biochars with $<0.6 \mathrm{H} / \mathrm{C}$ and $<0.4 \mathrm{O} / \mathrm{C}$ would be suitable for soil amendment and carbon sequestration, as biochars with low atomic $\mathrm{O} / \mathrm{C}$ could endure in soil for hundreds of years (longterm stability). ${ }^{62}$

The addition of HDPE has positive impacts on the HHV of biochars in most cases, especially in RH50 biochars. The higher HDPE fraction generally results in an increased heating value of blended biochars obtained at $400{ }^{\circ} \mathrm{C}$; whereas only small HHV changes are observed for blended biochars obtained at 500 and $600{ }^{\circ} \mathrm{C}$. The increase of HHV is associated with changes in proximate compositions. ${ }^{57}$ RH50 has the lowest initial ash content and the biochar obtained at $400{ }^{\circ} \mathrm{C}$ is with the highest VM and FC content, leading to the highest HHV, $\sim 30-32 \mathrm{MJ} / \mathrm{kg}$, whereas blended biochars produced at 500 and $600{ }^{\circ} \mathrm{C}$ are with lower combustible fractions. Most volatiles from HDPE are released to the gas phase when the temperature is greater than the main decomposition temperature of HDPE, resulting in lowered HHV of blended biochars obtained at 500 and $600{ }^{\circ} \mathrm{C}$. For instance, $\sim 30 \%$ reduction in HHV of RH50 biochar is found when the temperature increases from 400 to $500{ }^{\circ} \mathrm{C}$ (from 30.01 to $20.62 \mathrm{MJ} / \mathrm{kg}$ ) and from 400 to $600{ }^{\circ} \mathrm{C}$ (from 30.01 to $19.56 \mathrm{MJ} / \mathrm{kg}$ ), which is also reflected by the decrease of combustible fractions in the biochar: from 85.19 to 62.51 and $60.51 \mathrm{wt} \%$ when the temperature is increased from 400 to 500 and $600{ }^{\circ} \mathrm{C}$, respectively.

3.3.2. Structural Analysis. The chemical structure analysis results from FTIR, BET, and SEM on the selected biochars are shown in Figures 9-11 and listed in Table 3. The functional

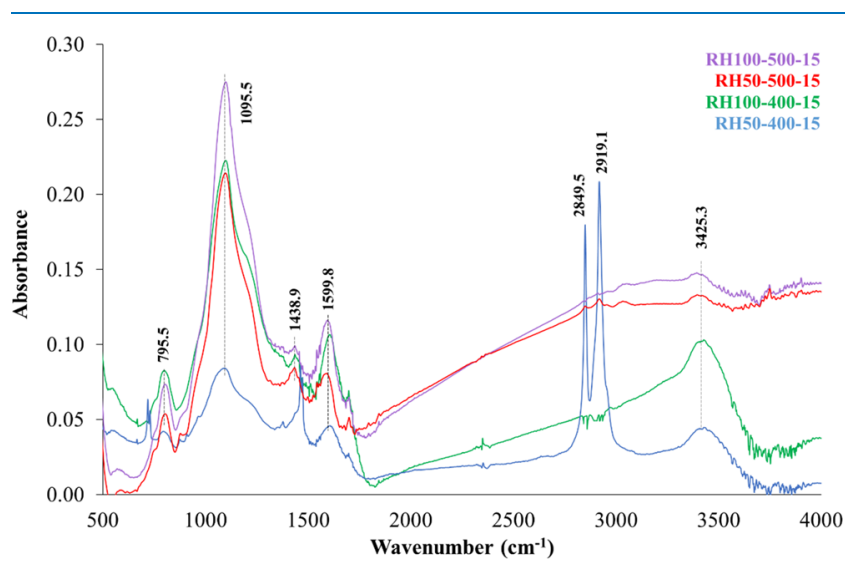

Figure 9. FTIR spectra of selected biochars (RH100-400-15, RH50400-15, RH100-500-15, and RH50-500-15).

Table 3. Surface Properties of the Selected Biochar Samples

$\begin{array}{lccc}\text { biochar sample } & \begin{array}{c}\text { surface area } \\ \left(\mathrm{m}^{2} / \mathrm{g}\right)\end{array} & \begin{array}{c}\text { pore volume } \\ \left(\times 10^{-4} \mathrm{~cm}^{3} / \mathrm{g}\right)\end{array} & \begin{array}{c}\text { average pore size } \\ (\mathrm{nm})\end{array} \\ \text { RH100-400-15 } & 1.546 & 88.576 & 22.913 \\ \text { RH100-500-15 } & 2.585 & 75.832 & 117.330 \\ \text { RH50-400-15 } & 0.286 & 5.580 & 8.137 \\ \text { RH50-500-15 } & 2.036 & 107.30 & 210.860\end{array}$



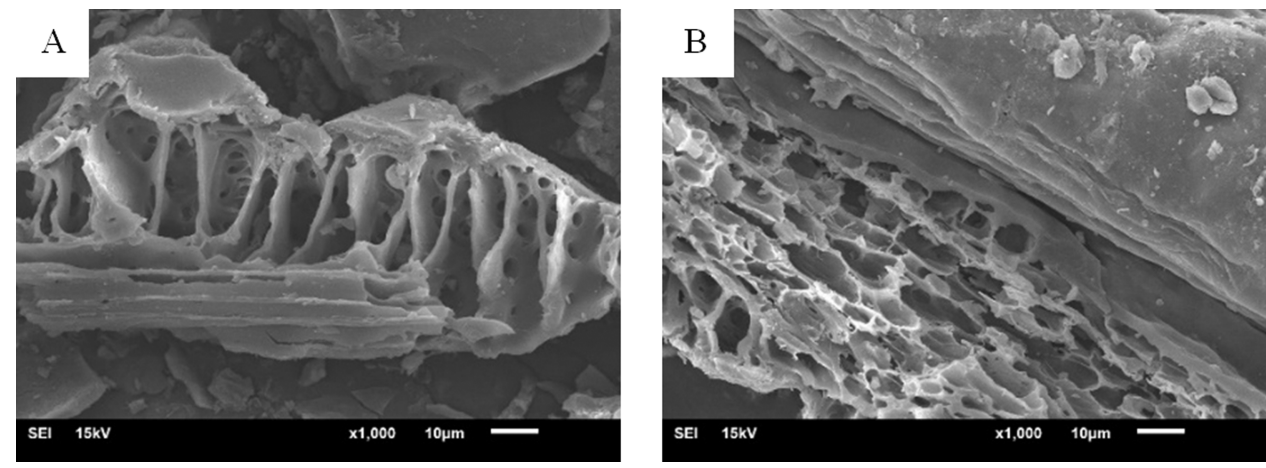

Figure 10. Scanning electron microscopy images of RH100-400-15 at magnification 1000× under (A) zone 1 and (B) zone 2 .
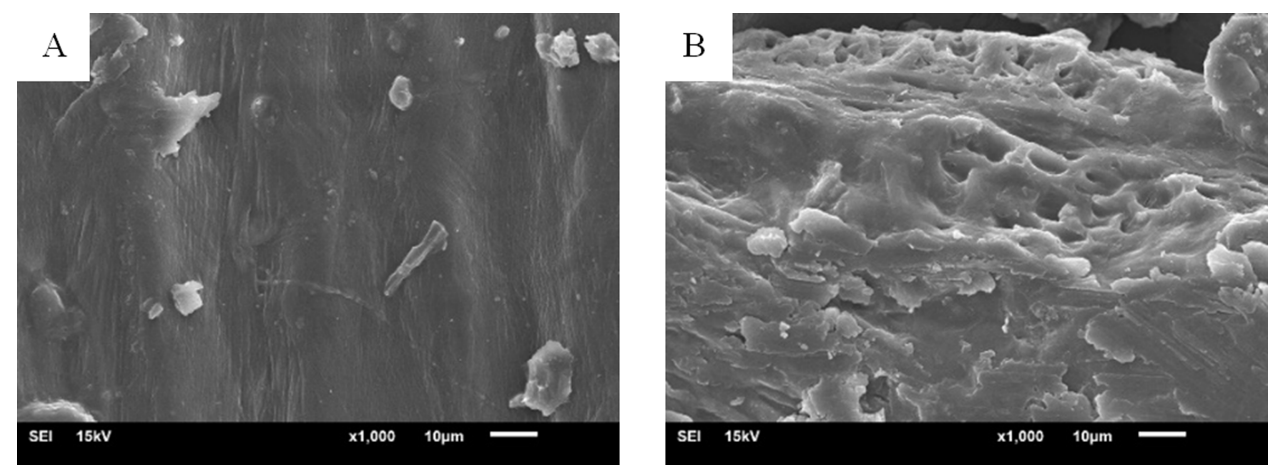

Figure 11. Scanning electron microscopy images of RH50-400-15 at magnification $1000 \times$ under (A) zone 1 and (B) zone 2.

groups of the biochar samples are identified using reference peaks. ${ }^{57,74,75}$ The band at $3400 \mathrm{~cm}^{-1}$ is attributed to stretching vibrations of $\mathrm{O}-\mathrm{H}$. Distinct peaks are observed at 2915 and $2850 \mathrm{~cm}^{-1}$; indicating asymmetric and symmetric stretching of $\mathrm{C}-\mathrm{H}$ in $-\mathrm{CH}_{2}$ groups from the polyethylene matrix. The absorption peak at around $1600 \mathrm{~cm}^{-1}$ relates to deformation vibrations of the water molecules $\left(\delta-\mathrm{H}_{2} \mathrm{O}\right)$ and the aromatic groups in lignin ( $\mathrm{C}=\mathrm{C}$ stretching) that are normally found in biochars. The peak at $1470 \mathrm{~cm}^{-1}$ is the $\mathrm{C}-\mathrm{H}$ bending band of $\mathrm{CH}_{2}$ groups. In addition, the peak at $\sim 1435 \mathrm{~cm}^{-1}$ is defined as $\mathrm{CH}$ deformation in the lignin and carbohydrates (cellulose and hemicellulose). Moreover, the most intense band at $1099 \mathrm{~cm}^{-1}$ corresponds to the vibration of silicon-oxygen tetrahedrons $\left(\mathrm{SiO}_{4}\right)$ and the main vibrations of the $\mathrm{C}-\mathrm{OH}$ bond in cellulose. The absorption peak at $790 \mathrm{~cm}^{-1}$ represents the presence of symmetric vibration of the $\mathrm{Si}-\mathrm{O}-\mathrm{Si}$ bond. Finally, the peak at $\sim 720 \mathrm{~cm}^{-1}$ is also attributed to the $\mathrm{CH}_{2}$ rocking mode.

The impacts of temperature can be identified from the $\mathrm{O}-\mathrm{H}$ functional group at $3400 \mathrm{~cm}^{-1}$ in $\mathrm{RH}$ and blended biochars. The increase of temperature leads to more release of free and intermolecular-bonded hydroxyl groups $-\mathrm{OH}$ between cellulose chains. Thus, the peak is more significant in RH100-400-15 and RH50-400-15 samples but almost disappears in RH100-500-15 and RH50-500-15 samples. The decrease in $\mathrm{O}-\mathrm{H}$ stretching illustrates an improvement in hydrophobicity of the biochar due to dehydration, resulting in improved fuel stability during fuel storage and handling in humid environments. ${ }^{74}$ The RH biochars (RH100-400-15 and RH100-500-15) have a significant peak at $1600 \mathrm{~cm}^{-1}$, representing the remnants of some lignin fragments and intermediate structures. The intensity of this peak, however, is weakened in copyrolysis of biochars (RH50-400-15 and RH50500-15) owing to the decreased lignin content of the feedstocks replaced by HPDE. Moreover, the presence of the peaks at $2915,2850,1470$, and $720 \mathrm{~cm}^{-1}$ is associated with the addition of HDPE in RH50-400-15, but these peaks almost disappear in RH50-500-15. Peaks at 1435, 1099, and $\sim 790$ $\mathrm{cm}^{-1}$ derived from the chemical structure of $\mathrm{RH}$ still exist in the blended sample at $500{ }^{\circ} \mathrm{C}$ ( $\left.\mathrm{RH} 50-500-15\right)$, indicating that the addition of HDPE has fewer impacts on the biochar chemical structure under the higher pyrolysis temperature conditions, as HDPE is mostly evaporated (especially when the pyrolysis temperature is higher than the decomposition temperature of plastic).

As biochar can be also utilized as low-cost natural adsorbents, the surface area, pore volume, pore size, and morphology of the biochar obtained are characterized and shown in Table 3 and Figures 10 and 11. Overall, the BET surface area of biochar increases with pyrolysis temperature due to the decomposition of hemicellulose, the depolymerization of cellulose, and the partial degradation of lignin. The VM, therefore, is released from the biochar matrix, forming voids or pores. $^{57,64,76}$ An increased surface area is observed in both $\mathrm{RH}$ biochar and blended biochar when the temperature is increased from 400 to $500{ }^{\circ} \mathrm{C}$. The surface area of $\mathrm{RH} 100$ $500-15$ is $\sim 1.67$ times higher than that of RH100-400-15 but with a smaller pore volume due to the destruction of pore walls under higher pyrolysis temperature conditions. ${ }^{64,77}$ Similar phenomena are also observed in blended biochars except for the larger average pore size in RH50-500-15. Moreover, the pore type increases from mesopore $(2-50 \mathrm{~nm})$ to macropore $(>50 \mathrm{~nm})$ when the temperature is increased from 400 to 500 ${ }^{\circ} \mathrm{C}$.

A drastic reduction of surface area, more than five times, is observed when 50 wt \% HDPE is added to the feedstock (RH50-400-15), as HDPE in RH50 melted rather than evaporated at $400{ }^{\circ} \mathrm{C}$. A different trend, however, is observed 
when comparing the $\mathrm{RH}$ biochars to blended biochars obtained at $500{ }^{\circ} \mathrm{C}$ (RH100-500-15 and RH50-500-15), i.e., a slightly reduced surface area of RH50-500-15, 20\% (relative). The pore volume and size, however, both increase in blended biochar at $500{ }^{\circ} \mathrm{C}$ due to the release of volatiles from HDPE via thermal decomposition, resulting in a higher pore volume and larger pore size. Thus, the pyrolysis temperature is crucial for the production of biochars through copyrolysis of biomass and plastics.

The morphology of RH biochar (RH100-400-15) analyzed by SEM exhibits an amorphous structure with some irregularshaped holes due to dehydration and devolatilization of cellulose. $^{75}$ The regular pore structures, however, all disappear in blended biochar (RH50-400-15). The surface is smoother with almost no developed pores, which is similar to the SEM image of plastic waste materials presented by Zhou et al. ${ }^{21}$ Melted HDPE may cover and block existing holes and voids in the biochar. Besides, the RH biochar is also capable of adsorbing some volatile species (VOCs) from HDPE. ${ }^{78}$ As RH50-400-15 biochar has a relatively low surface area and porosity, it cannot be employed as an adsorbent. The copyrolysis biochar obtained at higher temperatures (e.g., RH50-500-15), however, may be applied for adsorption.

3.4. Energy and Fixed Carbon Yields. The energy $\left(\eta_{\mathrm{E}}\right)$ and fixed carbon yield $\left(Y_{\mathrm{fc}}\right)$ are calculated and plotted as a function of the HDPE fraction in the feedstocks in Figure 12 to

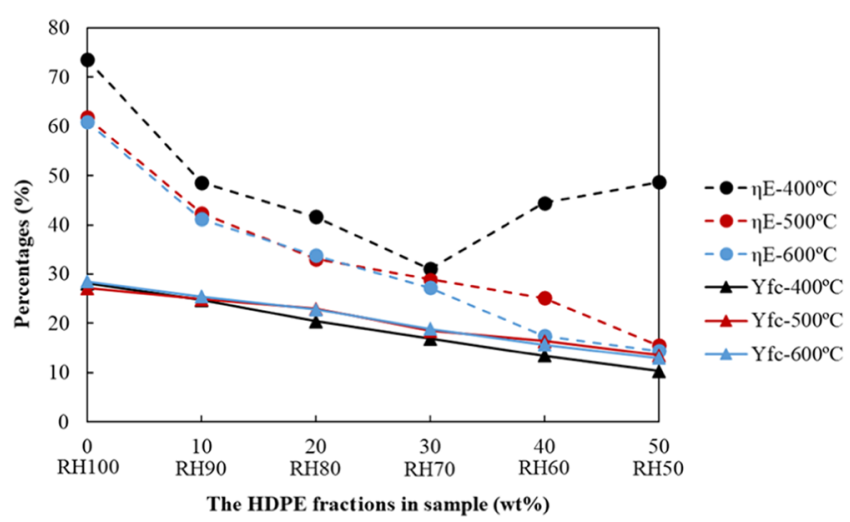

Figure 12. Yields of energy $\left(\eta_{\mathrm{E}}\right)$ and fixed carbon $\left(Y_{\mathrm{fc}}\right)$ for blended biochars at a constant holding time of $15 \mathrm{~min}$ (Figures S7 and S8 refer to the yields of energy $\left(\eta_{\mathrm{E}}\right)$ and fixed carbon $\left(Y_{\mathrm{fc}}\right)$ for blended biochars at constant holding times of 30 and $45 \mathrm{~min}$, respectively).

evaluate the feasibility of blended biochar to be used as a solid fuel. $\eta_{\mathrm{E}}$ represents the amount of energy retained in biochars after the pyrolysis process, whereas $Y_{\mathrm{fc}}$ is an economic parameter to evaluate the performance of the carbonization process. ${ }^{79}$ The higher the $\eta_{\mathrm{E}}$ and $Y_{\mathrm{fc}}$ of biochars, the greater the economic feasibility for biochar to be used as a solid fuel.

In general, $\eta_{\mathrm{E}}$ mainly depends on biochar yields and biomass types. ${ }^{80}$ The maximum $\eta_{\mathrm{E}},>70 \%$, is achieved for $\mathrm{RH}$ biochar produced at the lowest pyrolysis temperature, i.e., $400{ }^{\circ} \mathrm{C}$, whereas the lowest $\eta_{\mathrm{E}}$ is found for $\mathrm{RH}$ biochar obtained at the highest temperature with the longest holding time, only $\sim 55 \%$ (RH100-600-45), resulting from the increased degradation of hemicellulose, cellulose, and lignin under elevated temperatures. Similar results were reported by Matali et al. ${ }^{81}$ on torrefaction of woody biomass. About 28 wt \% reduction in the $\eta_{\mathrm{E}}$ was observed from 99.20 to $71.20 \%$ when the temperature was increased from 200 to $300{ }^{\circ} \mathrm{C}$.
The $\eta_{\mathrm{E}}$ drops continuously with an increase of HDPE fraction in feedstock for the copyrolysis process, except for RH60 and RH50 biochars at $400{ }^{\circ} \mathrm{C}$, for which the HHV of the blended biochars is greater than that of the corresponding $\mathrm{RH}$ biochars owing to the existence of HDPE residues. The $\eta_{\mathrm{E}}$ values for these RH60 and RH50 biochars, however, are still lower than those for RH100 biochars obtained under the same pyrolysis conditions. Although the $\mathrm{HHV}$ of the blended biochars does not change significantly with the HDPE fraction in feedstocks, the $\eta_{\mathrm{E}}$ continuously decreases with an increase of pyrolysis temperature and reaches the minimum value of $\sim 15 \%$.

The impact of feedstock HDPE ratios on $Y_{\mathrm{fc}}$ is similar to that on $\eta_{\mathrm{E}}$. A continuous decrease in $Y_{\mathrm{fc}}$ is observed, from 28 to $12 \%$, when the HDPE fraction increases from 0 (RH100) to 50 wt \% (RH50), which is also associated with the decrease of FC content and biochar yield. Operating parameters (temperature and holding time) slightly affect the $Y_{\mathrm{fc}}$. Although higher temperatures usually result in biochars with higher FC contents, the $Y_{\mathrm{fc}}$ only slightly changes, in a range of 25.3$28.5 \%$ under all testing conditions. Thus, the copyrolysis of biomass and plastic would not offer economic feasibility when only considering solid fuel production.

\section{CONCLUSIONS}

Biochar yields and properties from copyrolysis of $\mathrm{RH}$ and HDPE were investigated in the temperature range of 400-600 ${ }^{\circ} \mathrm{C}$ with $15-45 \mathrm{~min}$ holding periods. The operating parameters exhibited similar impacts on both $\mathrm{RH}$ pyrolysis and copyrolysis. The yields and physicochemical properties of biochar were mainly affected by pyrolysis temperature, and the impact of holding time is very limited. The biochar yields decrease with an increase of temperature for $\mathrm{RH}$ pyrolysis with 53-55 wt $\%$ maximum yield at $400{ }^{\circ} \mathrm{C}$, but no significant impact of temperature on the $\mathrm{HHV}$ of biochar was observed. A similar trend was observed for the copyrolysis process, and the highest blended biochar yields were also obtained at $400{ }^{\circ} \mathrm{C}, 33-56 \mathrm{wt}$ $\%$.

The fraction of HDPE was found to significantly affect both the quality and quantity of blended biochars produced. Blended biochar yields gradually decrease with an increase of HDPE fraction in the feedstock (from 10 to $50 \mathrm{wt} \%$ ) at 500 and $600{ }^{\circ} \mathrm{C}$ but increase with the HDPE fraction at $400{ }^{\circ} \mathrm{C}$, which is associated with the incomplete degradation at $400{ }^{\circ} \mathrm{C}$. Negative synergistic effects on blended biochar production, however, were observed. The addition of 10-20 wt \% HDPE improves the quality of biochar based on FC and $\mathrm{C}$ analyses, but a further increase of plastic fraction (30-50 wt \%) would have negative impacts on the biochar quantity, especially under low-temperature conditions, e.g., $400{ }^{\circ} \mathrm{C}$, at which the heat transfer of the blended samples was hindered due to the agglomeration of particles. Although the $\mathrm{HHV}$ was improved at $400{ }^{\circ} \mathrm{C}$ with a maximum value of $30 \mathrm{MJ} / \mathrm{kg}$ for $\mathrm{RH} 50$ biochars, it mainly results from an increase in volatile matter from melted HDPE. The $\eta_{\mathrm{E}}$ and $Y_{\mathrm{fc}}$ analyses, however, illustrate that solid fuel application of the blended biochars from copyrolysis has lower economic benefits in comparison with those of RH pyrolysis. Thus, the solid-, liquid-, and gasphase products should all be considered for process evaluation in future studies. 


\section{ASSOCIATED CONTENT}

\section{(s) Supporting Information}

The Supporting Information is available free of charge at https://pubs.acs.org/doi/10.1021/acsomega.1c03874.

Additional data on biochar yields, Van Krevelen diagrams, energy yields, and fixed carbon yields for 30 and 45 min holding times; nature of materials: recycled graded HDPE pellet of $4 \times 4 \mathrm{~mm}^{2}$ and ground raw rice husk of $0.5-1.0 \mathrm{~mm}$ (PDF)

\section{AUTHOR INFORMATION}

\section{Corresponding Author}

Nichakorn Wantaneeyakul - Department of Environmental Engineering, King Mongkut's University of Technology Thonburi (KMUTT), Bangkok 10140, Thailand; (1) orcid.org/0000-0001-7414-6991; Phone: +66 80 8065959; Email: nichakorn.w@mail.kmutt.ac.th

\section{Authors}

Ketwalee Kositkanawuth - Department of Environmental Engineering, King Mongkut's University of Technology Thonburi (KMUTT), Bangkok 10140, Thailand

Scott Q. Turn - Hawaii Natural Energy Institute, University of Hawaii at Manoa, Honolulu, Hawaii 96822, United States

Jinxia Fu - Hawaii Natural Energy Institute, University of Hawaii at Manoa, Honolulu, Hawaii 96822, United States;

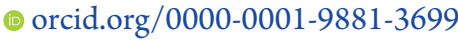

Complete contact information is available at: https://pubs.acs.org/10.1021/acsomega.1c03874

\section{Notes}

The authors declare no competing financial interest.

\section{ACKNOWLEDGMENTS}

This work was supported by the Petchra Pra Jom Klao Master's Degree Research Scholarship from King Mongkut's University of Technology Thonburi.

\section{REFERENCES}

(1) International Energy Agency. Statistic Report: Overview Renewables Information, 2020. https://www.iea.org/reports/ renewables-information-overview (accessed December 25, 2020).

(2) World Bioenergy Association. Global Bioenergy Statistics 2020, 2021. http:// www.worldbioenergy.org/uploads / 201210\%20WBA\%20GBS\%202020.pdf (accessed September 26, 2021).

(3) Energy Policy and Planning Office (Ministry of Energy). Alternative Energy Development Plan 2015-2036, 2020. https:// www.dede.go.th/download/files/PPT_AEDP2015.pdf (accessed December 25, 2020).

(4) Ministry of Energy. Alternative Energy Development Plan 2015-2036, 2020. https://www.dede.go.th/download/files/ AEDP\%20Action\%20Plan_Final.pdf (accessed December 25, 2020).

(5) TechnologyChaoBan, Department of Agricultural Extension in the Celebration of Thai Royal Coronation, Invited the Farmers to Create the Value from Their Farm, 2020. https://www. technologychaoban.com/bullet-news-today/article_107930 (accessed December 25, 2020)

(6) Full Advantage Co., Ltd. (Thailand), Simosol, O. (Finland), Institute of Energy (Vietnam), and Energy Conservation Research and Development Center (Vietnam). Final Report on Biomass Atlas for Vietnam, 2020. http://documents1.worldbank.org/curated/en/
428301536212059608 /pdf/Final-Report-on-BiomassAtlas-forVietnam.pdf (accessed December 25, 2020).

(7) Bhuvaneshwari, S.; Hettiarachchi, H.; Meegoda, J. N. Crop residue burning in India: Policy challenges and potential solutions. Int. J. Environ. Res. Public Health. 2019, 16, No. 832.

(8) Ministry of Agriculture and Cooperatives. ASEAN Food Security Information System, 2020. http://www.aptfsis.org/uploads/normal/ ACO\%20Report\%2019/ACOreport\%20no19 (accessed July 29, 2020).

(9) Pode, R. Potential applications of rice husk ash waste from rice husk biomass power plant. Renewable Sustainable Energy Rev. 2016, 53, 1468-1485.

(10) Biswas, B.; Pandey, N.; Bisht, Y.; Singh, R.; Kumar, J.; Bhaskar, T. Pyrolysis of agricultural biomass residues: Comparative study of corn cob, wheat straw, rice straw and rice husk. Bioresour. Technol. 2017, 237, 57-63.

(11) Abnisa, F.; Daud, W. M. A. W. A review on co- pyrolysis of biomass: An optional technique to obtain a high-grade pyrolysis oil. Energy Convers. Manage. 2014, 87, 71-85.

(12) The World Bank. Tackling Increasing Plastic Waste, 2021. https://datatopics.worldbank.org/what-a-waste/tackling_increasing plastic_waste.html (accessed July 26, 2021).

(13) Liang, Y.; Tan, Q.; Song, Q.; Li, J. An analysis of the plastic waste trade and management in Asia. Waste Manage. 2021, 119, 242253.

(14) United Nations Centre for Regional Development. State of Plastics Waste in Asia and the-Pacific-Issues, Challenges and Circular Economic Opportunities, 2021. http://www.env.go.jp/press/ State $\% 20$ of\%20 Plastics $\% 20$ Report $\% 20$ - \%2 007 Dec 2020 FINAL\%20FINAL\%20FINAL.pdf (accessed July 26, 2021).

(15) Pollution Control Department. Thailand State of Pollution Report 2019, 2021. https://www.pcd.go.th/wp-content/uploads/ 2020/09/pcdnew-2020-09-03_08-10-17_397681.pdf (accessed July 26, 2021).

(16) Law, K. L.; Starr, N.; Siegler, T. R.; Jambeck, J. R.; Mallos, N. J.; Leonard, G. H. The United States' contribution of plastic waste to land and ocean. Sci. Adv. 2020, 6, No. eabd0288.

(17) Jang, T. Thailand Ranks 5th in the World for Generating the Most Plastic Waste Per Population in the World, Found at $70 \mathrm{~kg}$ Per Person Per Year, 2021. https://www.bltbangkok.com/news/30658/ (accessed July 26, 2021).

(18) Oyedun, A. O.; Tee, C. Z.; Hanson, S.; Hui, C. W. Thermogravimetric analysis of the pyrolysis characteristics and kinetics of plastics and biomass blends. Fuel Process. Technol. 2014, 128, 471-481.

(19) Zhou, L.; Wang, Y.; Huang, Q.; Cai, J. Thermogravimetric characteristics and kinetic of plastic and biomass blends co-pyrolysis. Fuel Process. Technol. 2006, 87, 963-969.

(20) Rutkowski, P. Influence of zinc chloride addition on the chemical structure of bio-oil obtained during co-pyrolysis of wood/ synthetic polymer blends. Waste Manage. 2009, 29, 2983-2993.

(21) Zhou, X.; Nolte, M. W.; Shanks, B. H.; Broadbelt, L. J. Experimental and mechanistic modeling of fast pyrolysis of neat glucose-based carbohydrates. 2.Validation and evaluation of the mechanistic model. Ind. Eng. Chem. Res. 2014, 53, 13290-13301.

(22) Babu, B. V. Biomass pyrolysis: a state-of the-art review. Biofuels, Bioprod. Biorefin. 2008, 2, 393-414.

(23) Di-Blasi, C. Modeling chemical and physical processes of wood and biomass pyrolysis. Prog. Energy Combust. Sci. 2008, 34, 47-90.

(24) Anca-Couce, A. Reaction mechanisms and multi-scale modelling of lignocellulosic biomass pyrolysis. Prog. Energy Combust. Sci. 2016, 53, 41-79.

(25) Johannes, I.; Tiikma, L.; Luik, H. Synergy in co-pyrolysis of oil shale and pine sawdust in autoclaves. J. Anal. Appl. Pyrolysis 2013, 104, 341-352.

(26) Tang, Z.; Chen, W.; Chen, Y.; Yang, H.; Chen, H. Co-pyrolysis of microalgae and plastic: Characteristics and interaction effects. Bioresour. Technol. 2019, 274, 145-152. 
(27) Chen, W.; Shi, S.; Zhang, J.; Chen, M.; Zhou, X. Co-pyrolysis of waste newspaper with high-density polyethylene: Synergistic effect and oil characterization. Energy Convers. Manage. 2016, 112, 41-48.

(28) Hossain, M. S.; Islam, M. R.; Rahman, M. S.; Kader, M. A.; Haniu, H. Biofuel from co-pyrolysis of solid tire waste and rice husk. Energy Procedia 2017, 110, 453-458.

(29) Yang, J.; Rizkiana, J.; Widayatno, W. B.; Karnjanakom, S.; Kaewpanha, M.; Hao, X.; Abudula, A.; Guan, G. Fast co-pyrolysis of low density polyethylene and biomass residue for oil production. Energy Convers. Manage. 2016, 120, 422-429.

(30) Lee, Y.; Park, J.; Ryu, C.; Gang, K. S.; Yang, W.; Park, Y. K.; Jung, J.; Hyun, S. Comparison of biochar properties from biomass residues produced by slow pyrolysis at $500^{\circ} \mathrm{C}$. Bioresour. Technol. 2013, 148, 196-201.

(31) Quispe, I.; Navia, R.; Kahhat, R. Energy potential from rice husk through direct combustion and fast pyrolysis: A review. Waste Manage. 2017, 59, 200-210.

(32) Dahmen, N.; Dinjus, E.; Kruse, A. Fuels-Hydrogen Productionl Biomass: Thermochemical Processes. In Encyclopedia of Electrochemical Power Sources, 1st ed.; Garche, J., Ed.; Elsevier Science, 2009; pp 259-267.

(33) Li, Y.; Khanal, S. K. Bioenergy: Principles and Applications, 1st ed.; Wiley Blackwell: USA, 2016; p 27.

(34) Kositkanawuth, K.; Bhatt, A.; Sattler, M.; Dennis, B. Renewable energy from waste: Investigation of co-pyrolysis between sargassum macroalgae and polystyrene. Energy Fuels 2017, 31, 5088-5096.

(35) ASTM D3172, Standard Practice for Proximate Analysis of Coal and Coke; ASTM International: West Conshohocken, PA, 2002.

(36) ASTM D3173, Standard Test Method for Moisture in the Analysis Sample of Coal and Coke; ASTM International: West Conshohocken, PA, 2011.

(37) ASTM D3175, Standard Test Method for Volatile Matter in the Analysis Sample of Coal and Coke; ASTM International: West Conshohocken, PA, 2007.

(38) Kai, X.; Yang, T.; Shen, S.; Li, R. TG-FTIR-MS study of synergistic effects during co-pyrolysis of corn stalk and high-density polyethylene (HDPE). Energy Convers. Manage. 2019, 181, 202-213.

(39) Kai, X.; Li, R.; Yang, T.; Shen, S.; Ji, Q.; Zhang, T. Study on the co-pyrolysis of rice straw and high-density polyethylene blends using TG-FTIR-MS. Energy Convers. Manage. 2017, 146, 20-33.

(40) Kumar, S.; Singh, R. K. Pyrolysis kinetics of waste high-density polyethylene using thermogravimetric analysis. Int. J. ChemTech Res. 2014, 6, 131-137.

(41) Neira-Velázquez, M. G.; Borjas-Ramos, J. J.; HernandezHernandez, E.; Hernandez Ramos, C. G.; Narro-Cespedes, R. I.; Hernandez-Gamez, J. F.; Ramos de Valle, L. F. Nanocomposites prepared with high density polyethylene and carbon nanofibers modified by ethylene plasma. Plasma Process. Polym. 2015, 12, 477485.

(42) Naqvi, S. R.; Uemura, Y.; Yusup, S. B. Catalytic pyrolysis of paddy husk in a drop type pyrolyzer for bio-oil production: The role of temperature and catalyst. J. Anal. Appl. Pyrolysis 2014, 106, 57-62.

(43) Chen, D.; Li, Y.; Cen, K.; Luo, M.; Li, H.; Lu, B. Pyrolysis polygeneration of poplar wood: Effect of heating rate and pyrolysis temperature. Bioresour. Technol. 2016, 218, 780-788.

(44) Park, H. J.; Park, Y. K.; Kim, J. S. Influence of reaction conditions and the char separation system on the production of biooil from radiata pine sawdust by fast pyrolysis. Fuel Process. Technol. 2008, 89, 797-802.

(45) Encinar, J. M.; Beltran, F. J.; Bernalte, A.; Ramiro, A.; Gonzàlez, J. F. Pyrolysis of two agricultural residues: olive and grape bagasse. Influence of particle size and temperature. Biomass Bioenergy 1996, 11, 397-409.

(46) Caglar, A.; Aydinli, B. Isothermal co-pyrolysis of hazelnut shell and ultra-high molecular weight polyethylene: The effect of temperature and composition on the amount of pyrolysis products. J. Anal. Appl. Pyrolysis 2009, 86, 304-309.
(47) Cai, H.; Ba, Z.; Yang, K.; Zhang, Q.; Zhao, K.; Gu, S. Pyrolysis characteristics of typical biomass thermoplastic composites. Results Phys. 2017, 7, 3230-3235.

(48) Abnisa, F.; Daud, W. M. A. W.; Ramalingam, S.; Azemi, M. N. B. M.; Sahu, J. N. Co-pyrolysis of palm shell and polystyrene waste mixtures to synthesis liquid fuel. Fuel 2013, 108, 311-318.

(49) Chauhan, R. S.; Gopinath, S.; Razdan, P.; Delattre, C.; Nirmala, G. S.; Natarajan, R. Thermal decomposition of expanded polystyrene in a pebble bed reactor to get higher liquid fraction yield at low temperatures. Waste Manage. 2008, 28, 2140-2145.

(50) Brebu, M.; Ucar, S.; Vasile, C.; Yanik, J. Co-pyrolysis of pine cone with synthetic polymers. Fuel 2010, 89, 1911-1918.

(51) Mohammed, I. Y.; Lim, C. H.; Kazi, F. K.; Yusup, S.; Lam, H. L.; Abakr, Y. A. Co-pyrolysis of rice husk with underutilized biomass species: A sustainable route for production of precursors for fuels and valuable chemicals. Waste Biomass Valorization 2017, 8, 911-921.

(52) Önal, E.; Uzun, B. B.; Pütün, A. E. An experimental study on bio-oil production from co-pyrolysis with potato skin and high-density polyethylene (HDPE). Fuel Process. Technol. 2012, 104, 365-370.

(53) Önal, E.; Uzun, B. B.; Pütün, A. E. Bio-oil production via copyrolysis of almond shell as biomass and high density polyethylene. Energy Convers. Manage. 2014, 78, 704-710.

(54) Chen, W.; Chen, M.; Zhou, X. Characterization of biochar obtained by co-pyrolysis of waste newspaper with high-density polyethylene. BioResources 2015, 10, 8253-8267.

(55) Fassinou, W. F.; Steene, L. V.; Toure, S.; Volle, G.; Girard, P. Pyrolysis of Pinus pinaster in a two-stage gasifier: Influence of processing parameters and thermal cracking of tar. Fuel Process. Technol. 2009, 90, 75-90.

(56) Kan, T.; Strezov, V.; Evans, T. J. Lignocellulosic biomass pyrolysis: A review of product properties and effects of pyrolysis parameters. Renewable Sustainable Energy Rev. 2016, 57, 1126-1140.

(57) Cai, J.; Li, B.; Chen, C.; Wang, J.; Zhao, M.; Zhang, K. Hydrothermal carbonization of tobacco stalk for fuel application. Bioresour. Technol. 2016, 220, 305-311.

(58) Volpe, R.; Messineo, A.; Millan, M. Carbon reactivity in biomass thermal breakdown. Fuel 2016, 183, 139-144.

(59) Ronsse, F.; Nachenius, R. W.; Prins, W. Carbonization of Biomass. In Recent Advances in Thermochemical Conversion of Biomass, 1st ed.; Pandey, A.; Bhaskar, T.; Stocker, M.; Sukumaran, R., Eds.; Elsevier, 2015; Chapter 11, pp 293-324.

(60) Pecha, B.; Garcia-Perez, M. Pyrolysis of Lignocellulosic Biomass: Oil, Char and Gas. In Bioenergy: Biomass to Biofuels; 1st ed.; Dahiya, A., Ed.; Academic Press: New York, 2015; Chapter 26, pp 413-442.

(61) Yadav, K.; Jagadevan, S. Influence of Process Parameters on Synthesis of Biochar by Pyrolysis of Biomass: An Alternative Source Of Energy. In Recent Advances in Pyrolysis; IntechOpen, 2020.

(62) Wijitkosum, S.; Jiwnok, P. Elemental composition of biochar obtained from agricultural waste for soil amendment and carbon sequestration. Appl. Sci. 2019, 9, No. 3980.

(63) Antal, M. J.; Gronil, M. The art, science, and technology of charcoal production. Ind. Eng. Chem. Res. 2003, 42, 1619-1640.

(64) Claoston, N.; Samsuri, A. W.; Husni, M. H. A.; Amran, M. S. $\mathrm{M}$. Effects of pyrolysis temperature on the physicochemical properties of empty fruit bunch and rice husk biochars. Waste Manage. Res. 2014, 32, 331-339.

(65) Angin, D. Effect of pyrolysis temperature and heating rate on biochar obtained from pyrolysis of safflower seed press cake. Bioresour. Technol. 2013, 128, 593-597.

(66) Oyedun, A. O.; Tee, C. Z.; Hanson, S.; Hui, C. W. Thermogravimetric analysis of the pyrolysis characteristics and kinetics of plastics and biomass blends. Fuel Process. Technol. 2014, 128, 471-481.

(67) Li, A.; Liu, H. L.; Wang, H.; Xu, H. B.; Jin, L. F.; Liu, J. L.; Hu, J. H. Effects of temperature and heating rate on the characteristics of molded bio-char. BioResources 2016, 11, 3259-3274. 
(68) Keiluweit, M.; Nico, P. S.; Johnson, M. G.; Kleber, M. Dynamic molecular structure of plant biomass-derived black carbon (biochar). Environ. Sci. Technol. 2010, 44, 1247-1253.

(69) Kloss, S.; Zehetner, F.; Dellantonio, A.; Hamid, R.; Ottner, F.; Liedtke, V.; Schwanninger, M.; Gerzabek, M. H.; Soja, G. Characterization of slow pyrolysis biochars: Effects of feedstocks and pyrolysis temperature on biochar properties. J. Environ. Qual. 2012, 41, 9901000 .

(70) Kaewtrakulchai, N.; Fuji, M.; Eiad-ua, A. Investigation of parametric effects on fuel characteristics of biochar obtained from agricultural wastes pyrolysis. J. Mater. Sci. 2018, 7, 333-339.

(71) Fu, P.; Yi, W.; Bai, X.; Li, Z.; Hu, S.; Xiang, J. Effect of temperature on gas composition and char structural features of pyrolyzed agricultural residues. Bioresour. Technol. 2011, 102, 82118219.

(72) Van der Stelt, M. J. C.; Gerhauser, H.; Kiel, J. H. A.; Ptasinski, K. J. Biomass upgrading by torrefaction for the production of biofuels: A review. Biomass Bioenergy 2011, 35, 3748-3762.

(73) Schimmelpfennig, S.; Glaser, B. One step forward toward characterization: Some important material properties to distinguish biochars. J. Environ. Qual. 2012, 41, 1001-1013.

(74) Liu, W. J.; Tian, K.; Jiang, H.; Zhang, X. S.; Yang, G. X. Preparation of liquid chemical feedstocks by co-pyrolysis of electronic waste and biomass without formation of polybrominated dibenzo-pdioxins. Bioresour. Technol. 2013, 128, 1-7.

(75) Kizito, S.; Wu, S.; Kirui, W. K.; Lei, M.; Lu, Q.; Bah, H.; Dong, R. Evaluation of slow pyrolyzed wood and rice husks biochar for adsorption of ammonium nitrogen from piggery manure anaerobic digestate slurry. Sci. Total Environ. 2015, 505, 102-112.

(76) Jeong, C. Y.; Dodla, S. K.; Wang, J. J. Fundamental and molecular composition characteristics of biochars produced from sugarcane and rice crop residues and by-products. Chemosphere 2016, 142, 4-13.

(77) Arenas, E.; Chejne, F. The effect of the activating agent and temperature on the porosity development of physically activated coal chars. Carbon 2004, 42, 2451-2455.

(78) Li, M.; Wu, S. C.; Peng, Y.; Shih, Y. Adsorption of volatile organic vapors by activated carbon derived from rice husk under various humidity conditions and its statistical evaluation by linear solvation energy relationships. Sep. Purif. Technol. 2016, 170, 102108.

(79) Skreiberg, Ø.; Wang, L.; Bach, Q.; Grønli, M. Carbonization pressure influence on fixed carbon yield. Chem. Eng. Trans. 2018, 65, $7-12$.

(80) Kim, Y. H.; Lee, S. M.; Lee, H. W.; Lee, J. W. Physical and chemical characteristics of products from the torrefaction of yellow poplar (Liriodendron tulipifera). Bioresour. Technol. 2012, 116, 120125.

(81) Matali, S.; Rahman, N. A.; Idris, S. S.; Yaacob, N.; Alias, A. B. Lignocellulosic biomass solid fuel properties enhancement via torrefaction. Procedia Eng. 2016, 148, 671-678. 